\title{
Spinal Cord Injury Enables Aromatic L-Amino Acid Decarboxylase Cells to Synthesize Monoamines
}

\author{
Jacob Wienecke, ${ }^{1,2 \star}$ Li-Qun Ren, ${ }^{1 \star}$ Hans Hultborn, ${ }^{1}$ Meng Chen, ${ }^{1}{ }^{\circledR}$ Morten Møller, ${ }^{1}$ Yifan Zhang, ${ }^{1}$ \\ and Mengliang Zhang ${ }^{1,3}$ \\ ${ }^{1}$ Department of Neuroscience and Pharmacology, ${ }^{2}$ Department of Nutrition, Exercise and Sports, University of Copenhagen, Copenhagen, DK-2200 \\ Copenhagen, Denmark, and ${ }^{3}$ Neuronano Research Center, Department of Experimental Medical Sciences, Lund University, SE-221 00 Lund, Sweden
}

\begin{abstract}
Serotonin (5-HT), an important modulator of both sensory and motor functions in the mammalian spinal cord, originates mainly in the raphe nuclei of the brainstem. However, following complete transection of the spinal cord, small amounts of 5-HT remain detectable below the lesion. It has been suggested, but not proven, that this residual 5-HT is produced by intraspinal 5-HT neurons. Here, we show by immunohistochemical techniques that cells containing the enzyme aromatic L-amino acid decarboxylase (AADC) occur not only near the central canal, as reported by others, but also in the intermediate zone and dorsal horn of the spinal gray matter. We show that, following complete transection of the rat spinal cord at S2 level, AADC cells distal to the lesion acquire the ability to produce 5-HT from its immediate precursor, 5-hydroxytryptophan. Our results indicate that this phenotypic change in spinal AADC cells is initiated by the loss of descending 5-HT projections due to spinal cord injury (SCI). By in vivo and in vitro electrophysiology, we show that 5-HT produced by AADC cells increases the excitability of spinal motoneurons. The phenotypic change in AADC cells appears to result from a loss of inhibition by descending 5-HT neurons and to be mediated by 5-HT1B receptors expressed by AADC cells. These findings indicate that AADC cells are a potential source of 5-HT at spinal levels below an SCI. The production of 5-HT by AADC cells, together with an upregulation of 5-HT2 receptors, offers a partial explanation of hyperreflexia below a chronic SCI.
\end{abstract}

Key words: 5-HTP; AADC; motoneuron; serotonin; spasticity; supersensitivity

\section{Introduction}

Spasticity, a common sequela of spinal cord injury (SCI), has multiple underlying mechanisms (Nielsen et al., 2007; Roy and Edgerton, 2012). Some studies suggest that serotonin (5-HT), an important modulator of both sensory and motor functions, may figure prominently in the etiology of post-SCI spasticity. Following disruption of their suprasegmental inputs, lower motoneurons become supersensitive to 5-HT (Bedard et al., 1979; Barbeau and Bédard, 1981), apparently due to dramatic upregulation of 5-HT2A and 2C receptors such as we have previously shown to occur below a complete spinal transection (Kong et al., 2010,

Received Sept. 8, 2013; revised July 21, 2014; accepted July 24, 2014.

Author contributions: J.W., L.-Q.R., H.H., and M.Z. designed research; J.W., L.-Q.R., H.H., M.C., M.M., Y.Z., and M.Z. performed research; J.W., L.-Q.R., M.C., Y.Z., and M.Z. analyzed data; J.W., H.H., and M.Z. wrote the paper.

This project was supported by the Lundbeck Foundation, the Danish Multiple Sclerosis Foundation, the Ludvig and Sara Elsass Foundation, Danish Medical Research Council, and the International Foundation for Research in Paraplegia. We thank Dr. Ole Kiehn and Dr. Brian Noga for critical reading and comments on this manuscript. We are grateful to Lillian Grøndahl and Louise Schou for technical assistance. Special thanks to Dr. Richard L. Roth for his valuable comments and thorough editing of the last version of this manuscript and Mr. Bo Drenov for helping with the preparation of Figure $6 \mathrm{~A}$.

*J.W. and L.-Q.R. contributed equally to this work.

The authors declare no competing financial interests.

Correspondence should be addressed to Mengliang Zhang, MD, PhD, Department of Neuroscience and Pharmacology, the Panum Institute, University of Copenhagen, Blegdamsvej 3, DK-2200 Copenhagen, Denmark. E-mail: mzhang@sund.ku.dk.

L.-Q. Ren's and M. Chen's present address: Laboratory of Spinal Injury and Rehabilitation, Chengde Medical College, Chengde, China.

DOI:10.1523/JNEUROSCI.3838-13.2014

Copyright $\odot 2014$ the authors $\quad 0270-6474 / 14 / 3411984-17 \$ 15.00 / 0$
2011; Ren et al., 2013). By facilitating persistent inward currents, 5-HT chronically lowers the firing threshold of spinal motoneurons (Harvey et al., 2006; Li et al., 2007), which results in the abnormal muscle activity. In mammals, nearly all of the 5-HT in the CNS originates in neurons of the brainstem raphe nuclei. Yet, following complete spinal transection, the 5-HT content of spinal cord segments below the lesion is $\sim 15 \%$ of normal (Clineschmidt et al., 1971; Magnusson, 1973; Schmidt and Jordan, 2000). Because the rat has only three to nine intraspinal 5-HT neurons, their contribution to this residual 5-HT pool must be insignificant (Newton et al., 1986; Newton and Hamill, 1988). However, cells containing aromatic L-amino acid decarboxylase (AADC), the enzyme that catalyzes the conversion of 5-hydroxytryptophan (5-HTP) to 5-HT and of L-dopa to dopamine (Lovenberg et al., 1962; Christenson et al., 1972), occur in many CNS regions (Hökfelt et al., 1973; Jaeger et al., 1984; Eaton et al., 1993; Kitahama et al., 2009). In the spinal cord, AADC cells have been described mainly around the central canal and normally do not contain monoamines (catecholamine or 5-HT; Jaeger et al., 1983; Nagatsu et al., 1988). One possible reason for the failure of AADC cells in the intact spinal cord to produce monoamines is that monoaminergic innervation from brainstem neurons suppresses AADC activity (Branchereau et al., 2002). We hypothesize that, following complete spinal cord transection and given a source of 5-HTP, AADC cells below the lesion can undergo a phenotypic change and begin producing $5-\mathrm{HT}$. The aims of this study are as follows: (1) to more fully characterize the AADC cells 
of the rat spinal cord; (2) to determine whether eliminating their postulated suppression by descending 5-HT input enhances the ability of AADC cells to convert 5-HTP to 5-HT; (3) to determine whether the excitability of motoneurons below an SCI is enhanced by locally produced 5-HT and, given affirmative findings for the two immediately preceding aims; (4) to explore the mechanisms whereby SCI enhances the ability of AADC cells to synthesize 5-HT. To achieve these aims, we adopted a sacral spinal cord transection model in which hyperreflexia and spasms of the tail develop in the chronic phase (Bennett et al., 1999). Our preliminary results have been reported previously in abstract form (Ren et al., 2012; Wienecke et al., 2012; Zhang et al., 2012).

\section{Materials and Methods}

Surgical procedures and tissue preparations. All experiments were conducted in accordance with the guidelines of EU Directive 2010/63/EU and were approved by the Danish Animal Experiments Inspectorate. In total, 120 (117 male and 3 female) adult Wistar rats, with an initial body weight of 100-200 g, from the Charles River Laboratories were used. The rats were either killed directly with or without perfusion after being anesthetized, underwent spinalization (excision of the spinal cord tissue underlying the vertebral lamina) at the sacral 2 (S2) spinal level, or were sham operated, i.e., only an L2 laminectomy was performed (Wienecke et al., 2010). Usually 2 weeks following spinalization the rats could be considered to be at a chronic stage (Bennett et al., 1999). In detail, two normal rats were killed with pentobarbital and used for Western blotting; three normal rats were directly perfused and used to study the distribution of AADC, 5-HT, NeuN (neuronal nuclei), nestin, doublecortin, choline acetyltransferase (ChAT), and 5-HT1B receptor immunostaining. Ten rats underwent either spinalization $(n=5)$ or sham operation $(n=5)$ and were perfused on the 45 th postoperative day to assess whether SCI causes changes in AADC expression at the protein level. Three normal and three chronically sham-operated rats were first injected with 5-HTP (100 mg/kg, i.p.) and three chronically spinalized rats were first injected with carbidopa $(20 \mathrm{mg} / \mathrm{kg}$, i.p) and 5-HTP $(100 \mathrm{mg} / \mathrm{kg}$, i.p.) and then perfused. Twenty-five spinalized rats were killed at different postoperative intervals (five each at $8 \mathrm{~h}, 1,2,5$, and $14 \mathrm{~d}$ ) to study the time course of 5-HT expression in AADC cells. Twelve chronically spinalized rats were used for 5-HT1B receptor agonist experiments; seven normal rats were used for 5-HT1B antagonist experiments. Thirty-eight chronically spinalized rats were used for in vivo experiments (including 12 for 5-HT1B agonist experiments), and 20 chronically spinalized rats were used for in vitro electrophysiological experiments.

For immunohistochemistry, the rats were transcardially perfused (either directly or after in vivo experiments) with $4 \%$ paraformaldehyde in $0.1 \mathrm{M}$ cold phosphate buffer and the spinal cords immediately removed and postfixed in the same fixative. The sacrocaudal spinal cords of the rats used for in vitro experiments were immersion fixed in $4 \%$ paraformaldehyde. After postfixation for $20-24 \mathrm{~h}$ at $4^{\circ} \mathrm{C}$, the spinal cords were cryoprotected in $0.01 \mathrm{M}$ PBS with $30 \%$ sucrose for up to $48 \mathrm{~h}$ at $4^{\circ} \mathrm{C}$. All sacrocaudal spinal cord segments were cut into $40-\mu \mathrm{m}$-thick transverse or horizontal sections. If not processed immediately, the tissue was frozen and stored at $-80^{\circ} \mathrm{C}$. The brains of all the rats were also removed: those of some normal rats were used for antibody control staining (see below) and the rest were reserved for future use.

Clinical assessment of tail spasticity. Before in vivo or in vitro experiments, which were conducted between the 35 th and 126 th postoperative day, the spinalized animals underwent a clinical assessment of tail spasticity, as described by Bennett et al. (1999) and Wienecke et al. (2010). Only those rats with spasticity scores of $4-5$, where 5 was the highest score, were used for electrophysiological experiments. Approximately 9 of 10 spinalized rats in this study reached these threshold scores by the 35 th postoperative day.

In vivo tail electromyography. All in vivo electrophysiological experiments used chronically spinalized rats. The detailed procedure for tail electromyography (EMG) recording has been described previously (Bennett et al., 2004). The rats were anesthetized with isoflurane while four sterile steel wires (Ethicon 4-0; Johnson \& Johnson) were sutured subcu- taneously into the tail 1-3 d before recordings. Two wires located rostrally were used for bilateral stimulation, and two wires located $3-4 \mathrm{~cm}$ caudal to the stimulating electrodes were used for recording. On the day of the experiment, the rat was placed in a tube with an opening at the end for the tail. Using wet gauze to ensure good contact, a ground electrode was mounted at the middle of the tail. When the rat was resting passively in the tube, the spontaneous activity decreased with time, partly due to inactivity and reduced blood circulation in the dependent tail (Bennett et al., 1999). To maintain adequate blood circulation, the tail was gently lifted for $10 \mathrm{~s}$ every $5 \mathrm{~min}$. In all rats, spontaneous tail EMG activity was recorded in two or three episodes of 20 min duration, with the first episode serving as the baseline. All data were sampled and analyzed with Spike2 software (Cambridge Electronic Design). The EMG signal was usually amplified 500-2,000 times with low-pass filtering at $10 \mathrm{kHz}$ and high-pass filtering at $100 \mathrm{~Hz}$.

As summarized in Figure $1 A$ and described somewhat more fully in what follows, we used five different experimental variants to maximize our understanding of activities in the spinal cord below the transection. (1) To establish whether spinal AADC cells below an SCI can convert systemically administered 5-HTP into 5-HT, three rats were given intraperitoneal injections of 5-HTP $(100 \mathrm{mg} / \mathrm{kg})$ in saline containing a small amount of $\mathrm{HCl}$. Four additional rats were injected intraperitoneally with 5-HTP $(20 \mathrm{mg} / \mathrm{kg})$ in combination with one of two monoamine oxidase inhibitors (MAOIs)-either nialamide, $150 \mathrm{mg} / \mathrm{kg}(n=2)$ or $N$-methyl- $N$ propargyl-3-(2,4, dichlorophenoxy) propylamine hydrochloride (clorgyline), $2 \mathrm{mg} / \mathrm{kg}(n=2$; Fig. 1Ai). (2) To investigate whether the effects of 5 -HTP can be prevented by an AADC inhibitor, six rats were injected with DL-serine 2-(2,3,4-trihydroxybenzyl) hydrazide (benserazide hydrochloride; $800 \mathrm{mg} / \mathrm{kg}$ in saline, i.p.; a dose found by Bedard et al., 1979 to inhibit all central AADC enzyme activity), followed 20 min later by 5-HTP $(100 \mathrm{mg} / \mathrm{kg}$; i.p.; Fig. 1Aii). (3) To confirm that the effects of 5-HTP on the increased tail motoneuron excitability were a result of the conversion of 5-HTP into 5-HT in the spinal cord below the lesion, five rats were injected intrathecally with $20-25 \mu \mathrm{l}$ of $5 \mathrm{~mm}$ benserazide hydrochloride, prepared in artificial CSF (aCSF), $1 \mathrm{~h}$ before intraperitoneal injection of 5-HTP $(100 \mathrm{mg} / \mathrm{kg})$. As controls, seven spinalized rats were similarly injected intrathecally with $20-25 \mu \mathrm{l}$ of unaltered aCSF $1 \mathrm{~h}$ before intraperitoneal injection of 5-HTP (Fig. 1Aiii). Care was taken to avoid damaging the sacrocaudal spinal roots by using a 30 gauge needle attached to a $50 \mu \mathrm{l}$ Hamilton syringe to deliver the injections into the subarachnoid space between lumbar vertebrae 1 and 3, where earlier surgery had removed the lamina and spine of the second lumbar vertebra and the underlying spinal cord tissue. (4) To investigate whether the effects of 5-HTP can be antagonized by 5-HT2 receptor antagonists, seven rats were injected with 5-HTP $(100 \mathrm{mg} / \mathrm{kg}$, i.p.), followed $20 \mathrm{~min}$ later by injection of the 5-HT2 receptor antagonist cyproheptadine hydrochloride sesquihydrate $(10 \mathrm{mg} / \mathrm{kg}$ in water with a small amount of ethanol, i.p.; Fig. 1Aiv). (5) To investigate the inhibitory effects of 5-HT1B receptor activation on the production of 5-HT from 5-HTP in AADC cells, spontaneous EMG activity was recorded in 12 rats, both before and after injection of CP94253 $(n=6)$ or saline $(n=6$; Fig. $1 A v$; see below, 5-HT1B receptor agonist and antagonist experiments for details).

In vitro experiments. All in vitro experiments used chronic spinalized rats and were performed according to Li et al. (2004). Following deep isoflurane anesthesia, a dorsal laminectomy from thoracic 13 to lumbar 6 was performed to expose the lumbar and sacrocaudal spinal cord. The spinal cord caudal to the transection was quickly removed and was placed in a dissection dish containing oxygenated modified aCSF at $20-21^{\circ} \mathrm{C}$ (for preparation, see below). After recovery in the dissection dish, the sacrocaudal cord was transferred to a recording chamber and bathed with normal aCSF flowing at $4.5 \mathrm{ml} / \mathrm{min}$ and maintained at $23-25^{\circ} \mathrm{C}$. Ventral and dorsal roots were placed into channels lateral to the main chamber, where the entrance was isolated with Vaseline gel. Monopolar recordings and stimulation were then performed using chloride silver electrode pairs in which one pole was located at the end of the respective channel of interest, and the other in a common pool close to the isolating Vaseline clot. In most cases, S4, Ca1, and/or Ca2 dorsal and ventral roots on either side of the cord were mounted. A ground electrode was placed 


\section{A Protocol for in vivo electrophysiological experiments}

i. In vivo 5-HTP effects on motoneuronal excitability

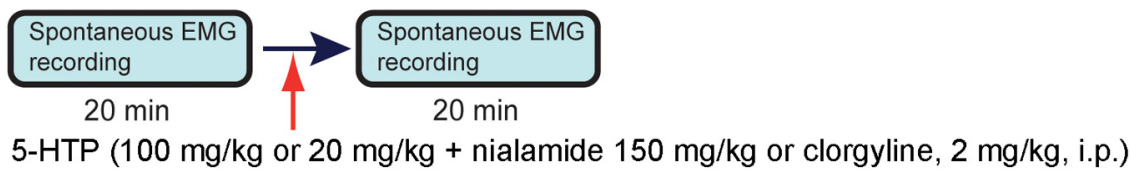

ii. 5-HTP effect blocking by AADC inhibitor, benserazide hydrochloride, i.p. injection

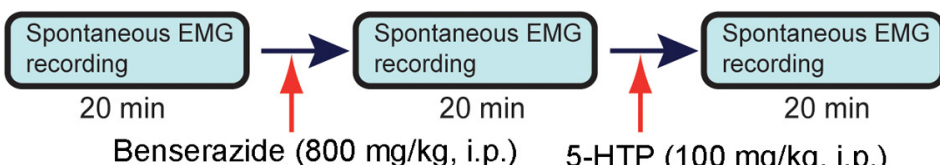

iii. 5-HTP effect blocking by AADC inhibitor, benserazide hydrochloride, i.t. application

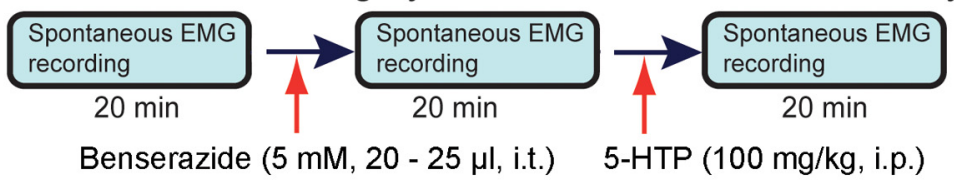

iv. 5-HTP effect blocking by 5-HT2 receptor antogonist, cyproheptadine

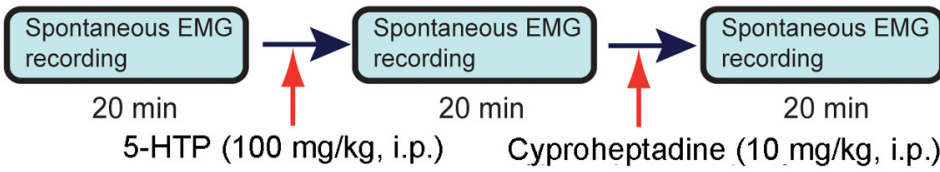

v. Effects of 5-HT1B agonist on motoneuronal excitability

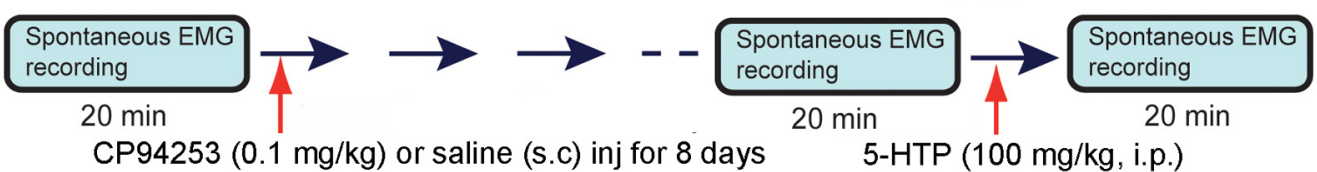

B Protocol for in vitro electrophysiological experiments

i. Dose response of spinal motoneurons to 5-HTP bath application

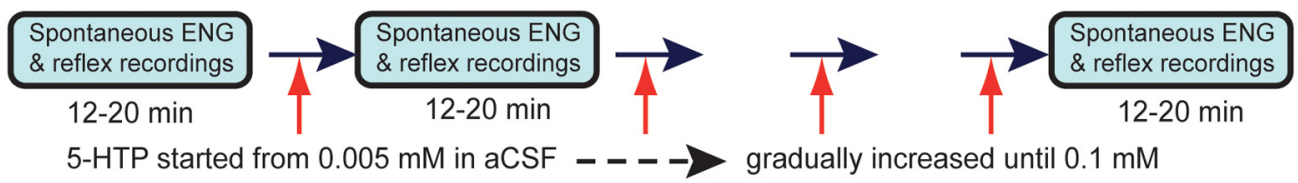

ii. AADC enzyme inhibition by benserazide hydrochloride via bath application

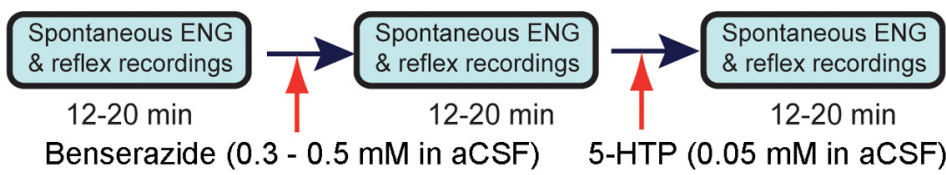

Figure 1. Protocols of in vivo and in vitro electrophysiological experiments conducted in this study. $\boldsymbol{A}$, Five different in vivo electrophysiological experiments were performed: $\boldsymbol{i}$, 5 -HTP intraperitoneal injection only, ii, AADC inhibition with benserazide hydrochloride before 5-HTP application, iii, Benserazide hydrochloride or aCSF intrathecal injection before 5-HTP intraperitoneal injection, iv, inhibition of 5-HTP effect with cyproheptadine; and $\boldsymbol{v}, 5$-HT1B agonist subcutaneous application. For all the experiments, spontaneous tail EMG activity was recorded before and after each drug administration. Each EMG recording lasted for $20 \mathrm{~min}$. The animal was perfused after the last recording. $\boldsymbol{B}$, Two different in vitro electrophysiological experiments were performed: $\boldsymbol{i}$, ENG response to different concentrations of 5-HTP in the bath solution (aCSF) and ii, inhibition of AADC with benserazide hydrochloride in aCSF bath before addition of 5-HTP.

in the main chamber. Dorsal roots were stimulated with $0.2 \mathrm{~ms}$ current pulses with stimulation strength up to $200 \mu \mathrm{A}$ (equal to $20-100 \times$ reflex threshold) every 10-20 s. Electroneurogram (ENG) signals from the ventral roots were amplified 5,000-10,000 times with high-pass filtering at $1-100 \mathrm{~Hz}$ and low-pass filtering at $5-10 \mathrm{kHz}$. The recording periods were usually $12-20 \mathrm{~min}$ for each step in the protocol (Figure $1 B$ ). Only the last 3-4 min of each recording period were used for analysis to ensure enough time for the drug to exert its effect. Spike2 was used for acquisition and analysis of the data. To establish the 5-HTP dose-response relationship, the sacrocaudal spinal cords of 10 spinalized rats were subjected to gradually increasing concentrations of 5-HTP (range: $0.005-0.1$ $\mathrm{mm}$ ) in the aCSF bath solution (Fig. $1 \mathrm{Bi}$ ). Another 10 rats were used for 
AADC enzyme inhibition experiments (in 7 of these rats, dorsal rootinduced long-lasting reflexes (LLRs) were recorded, as described by Bennett et al., 2004). For inhibition experiments, benserazide hydrochloride was added to the bath solution to a final concentration of $0.3-0.5 \mathrm{~mm}$. After $20 \mathrm{~min}, 5-\mathrm{HTP}$ was added to the bath solution to a final concentration of $0.05 \mathrm{~mm}$ (Fig. 1Bii).

5-HT1B receptor agonist and antagonist experiments. To investigate whether AADC activity in the production of 5 - $\mathrm{HT}$ is inhibited via a 5-HT1B feedforward mechanism, we examined the effects of a 5-HT1B agonist in chronically spinalized rats and of a 5-HT1B antagonist in normal rats. In six chronically spinalized rats, CP94253, a potent and selective 5-HT1B receptor agonist, was subcutaneously injected $(0.1$ $\mathrm{mg} / \mathrm{kg}$ daily) for 8 consecutive days. As a control, in six chronically spinalized rats, an equivalent volume of vehicle (saline) was administered in the same way. Following the last injection of agonist or saline, 5-HTP $(100 \mathrm{mg} / \mathrm{kg}$, i.p.) was injected, and $20 \mathrm{~min}$ later, the animal was perfused. Spontaneous tail EMG recording was performed as described above before the first CP94253/saline injection, and both before and after 5-HTP injection on the last day.

In five normal rats, $\mathrm{N}$-[3-[3-(Dimethylamino)ethoxy]-4-methoxyphenyl]-2' -methyl-4' -(5-methyl-1,2,4-oxadiazol-3-yl)-[1,1'-biphenyl]-4-carboxamide hydrochloride (SB216641), a selective 5-HT1B antagonist, was injected ( $6 \mathrm{mg} / \mathrm{kg}$ daily, s.c.) for 5 consecutive days. As a control, two rats were injected in the same way with an equivalent volume of vehicle. Three rats that were not injected with saline were used as additional controls. On the last day after the final drug/saline injection, 5 -HTP (100 mg/kg, i.p.) was injected, and the animal was perfused 20 min later.

Drugs and aCSF preparations. 5-HTP, nialamide, clorgyline, benserazide hydrochloride, and cyproheptadine were obtained from SigmaAldrich. CP94253 and SB216641were obtained from Tocris Bioscience. The normal aCSF used in the recording chamber was composed of the following (in mM): $122 \mathrm{NaCl}, 24 \mathrm{NaHCO}_{3}, 3 \mathrm{KCl}, 2.5 \mathrm{CaCl}_{2}, 1 \mathrm{MgSO}_{4}$, and 12 glucose made up in distilled water. The modified aCSF was composed of the following (in mM): $118 \mathrm{NaCl}, 24 \mathrm{NaHCO}_{3}, 3 \mathrm{KCl}, 1.5 \mathrm{CaCl}_{2}$, $5 \mathrm{MgCl}_{2}, 1.4 \mathrm{NaH}_{2} \mathrm{PO}_{4}, 1.3 \mathrm{MgSO}_{4}, 25$ glucose, and 1 kynurenic acid.

Western blotting. The AADC antibodies used were sheep anti-AADC (AB119; Millipore Bioscience Research Reagents) and rabbit anti-AADC (ab3905; Abcam) polyclonal antibodies. The antibodies were produced by immunizing the animals with recombinant bovine AADC proteins expressed in Escherichia coli and purified from inclusion bodies. To verify the specificity of the antibody, Western blotting was performed on neostriatal tissue from two rats. The detailed procedure for Western blotting has been described previously(Ren et al., 2013).

Time course study of 5-HT expression in AADC cells. Five groups of spinalized rats, each consisting of five individuals, were used to study the time course over which AADC cells acquire the ability to convert 5-HTP to 5-HT. Following postspinalization survival times of $8 \mathrm{~h}, 1,2$, 5, and $14 \mathrm{~d}$, the rats were injected with 5-HTP (100 mg/kg, i.p.) and killed 30 min later. Seven rats that had been used for in vivo tail EMG experiments 63-79 d after spinalization were also included in the time course study. The results from spinalized rats were compared with those from the normal $(n=3)$ and sham-operated rats $(n=3)$ similarly injected with 5-HTP.

Immunohistochemistry. To examine the expression of AADC, 5-HT, NeuN, nestin, doublecortin, ChAT, and 5-HT1B receptors in the normal and/or SCI rat spinal cord, either avidin-biotin complex (ABC) peroxidase or fluorescent immunostaining technique was used. The detailed immunohistochemical procedures have been described previously (Kong et al., 2010, 2011; Ren et al., 2013). ABC peroxidase immunohistochemistry was used for AADC staining of the sacrocaudal spinal cords of normal, $45 \mathrm{~d}$ sham-operated and $45 \mathrm{~d}$ spinalized rats. Sections were first incubated in sheep anti-AADC (1:400) primary antibody for 40-48 $\mathrm{h}$ at $4^{\circ} \mathrm{C}$ and then in biotinylated donkey anti-sheep $\operatorname{IgG}(1: 200 ; \mathrm{Abcam})$ for $1 \mathrm{~h}$ at room temperature. After incubation in $\mathrm{ABC}$ (1:100; Vector Laboratories), the reaction was visualized in $0.05 \%$ diaminobenzidine tetrahydrochloride (Sigma-Aldrich) with $0.005 \% \quad \mathrm{H}_{2} \mathrm{O}_{2}$. Doublefluorescence immunohistochemistry was used to characterize the AADC cells and to examine the relationships of different cellular structures in the spinal cord from normal and SCI rats. To determine whether AADC cells express 5-HT before and after 5-HTP application, AADC and 5-HT double immunostaining was performed on the spinal cords of most animals regardless of their operative histories. To examine whether AADC cells are mature neurons, immature neurons, or neuronal precursors, $\mathrm{AADC}$ and NeuN, doublecortin, or nestin double immunostaining was performed on selected sacrocaudal sections from normal rats. To examine whether AADC/5-HT fibers innervate the ventral horn motoneuron region, 5-HT and ChAT double immunostaining was performed on representative sacrocaudal spinal cord sections from the $\mathrm{S} 4$ and caudal (Ca) 1 segments of three normal and three spinalized rats. In the latter group, 5 -HTP $(100 \mathrm{mg} / \mathrm{kg})$ plus carbidopa $(20 \mathrm{mg} / \mathrm{kg})$ was intraperitoneally injected to enhance the expression of 5-HT in ADDC cells (see "Surgical procedures and tissue preparations" above). To examine whether AADC cells express 5-HT1B receptors, AADC and 5-HT1B double immunostaining was performed on selected sacrocaudal spinal cord sections from several normal and SCI rats. Sections were first incubated in primary antibodies as follows: (1) sheep anti-AADC (1:200) paired with rabbit anti-5-HT (1:500-10,000 depending on the lot, 20080; ImmunoStar) or mouse anti-NeuN (1:500, MAB377; Millipore Bioscience Research Reagents) or mouse anti-nestin (1:100, MAB353A4; Millipore Bioscience Research Reagents) or rabbit anti-doublecortin (1:500, ab18723; Abcam), (2) rabbit anti-AADC (1:500, ab3905; Abcam) paired with goat anti-5-HT1B (1:20-50, sc1461; Santa Cruz Biotechnology), and (3) rabbit anti-5-HT $(1: 10,000,20080$; ImmunoStar) paired with goat antiChAT (1:100, AB144; Millipore Bioscience Research Reagents). Appropriate pairs of secondary donkey-raised antibodies to sheep, rabbit, mouse, or goat and conjugated to Alexa Fluor 488 or 494 were then used to visualize the primary antibodies. Some sections processed for 5-HT1B were counterstained with a fluorescent cell nuclear marker, DAPI (4',6-diamidino-2-phenylindole, 1:100, S7113; Millipore Bioscience Research Reagents). All the fluorescent secondary antibodies were from Invitrogen. For AADC-positive control immunostaining, sections from the brainstem were also used. Control immunohistochemical staining was also performed using the same procedures with spinal cord and/or brainstem sections with the primary antibodies omitted. For AADC and 5-HT1B antibodies adsorption control experiments were also performed.

Data analysis. The spinal sections were observed with a conventional light microscope (Leica DM6000B; Leica Microsystems) or a confocal microscope (LSM 710, Carl Zeiss Microscopy). Images were captured digitally and processed with Adobe Photoshop CS5. For the quantitative analysis of AADC- or 5-HT-immunopositive cells, the MD Plotting System (AccuStage) was used. Alternate or every third spinal cord section from each animal was plotted, and the program was used to calculate the section area and the number of cells it contained. The volume of spinal cord tissue was determined by multiplying the area of a section by its thickness, and the density of AADC or 5-HT cells was expressed as cells per millimeter cubed. Because AADC cells in the intermediate zone were consistently labeled across different experimental groups, the percentage of 5-HT-immunopositive cells among the AADC-immunopositive cells was calculated for this region only.

Three spinalized and three normal rats were used to assess the innervation of motoneurons by 5 -HT-immunopositive fibers originating from AADC cells after SCI. The spinalized rats were injected intraperitoneally with carbidopa and 5-HTP; the normal rats served as untreated controls. As described previously (Kong et al., 2010), the ventral horn regions of spinal segments S4-Ca1 were subjected to quantitative analysis of 5-HT-immunoreactive fibers. Equal area (approximately $210 \times$ $210 \mu \mathrm{m})$ confocal images were made of spinal cord sections from normal and spinalized rats, and each image stack was maximum intensity averaged. Then a quantitative analysis of the optical density of 5-HT immunoreactivity was performed using NIH ImageJ software (version $1.45 \mathrm{~s}$, courtesy of Wayne Rasband, NIMH, Bethesda, MD). Each image was first "thresholded" so that only pixels above the threshold level were counted as definitively labeled elements (Fig. 5A3,B3). The pixel area occupied by 5 -HT-immunopositive elements exceeding the threshold level was measured, and the portion of the total study area occupied by labeled pixels was expressed as a decimal fraction. For each rat, $8-10$ 

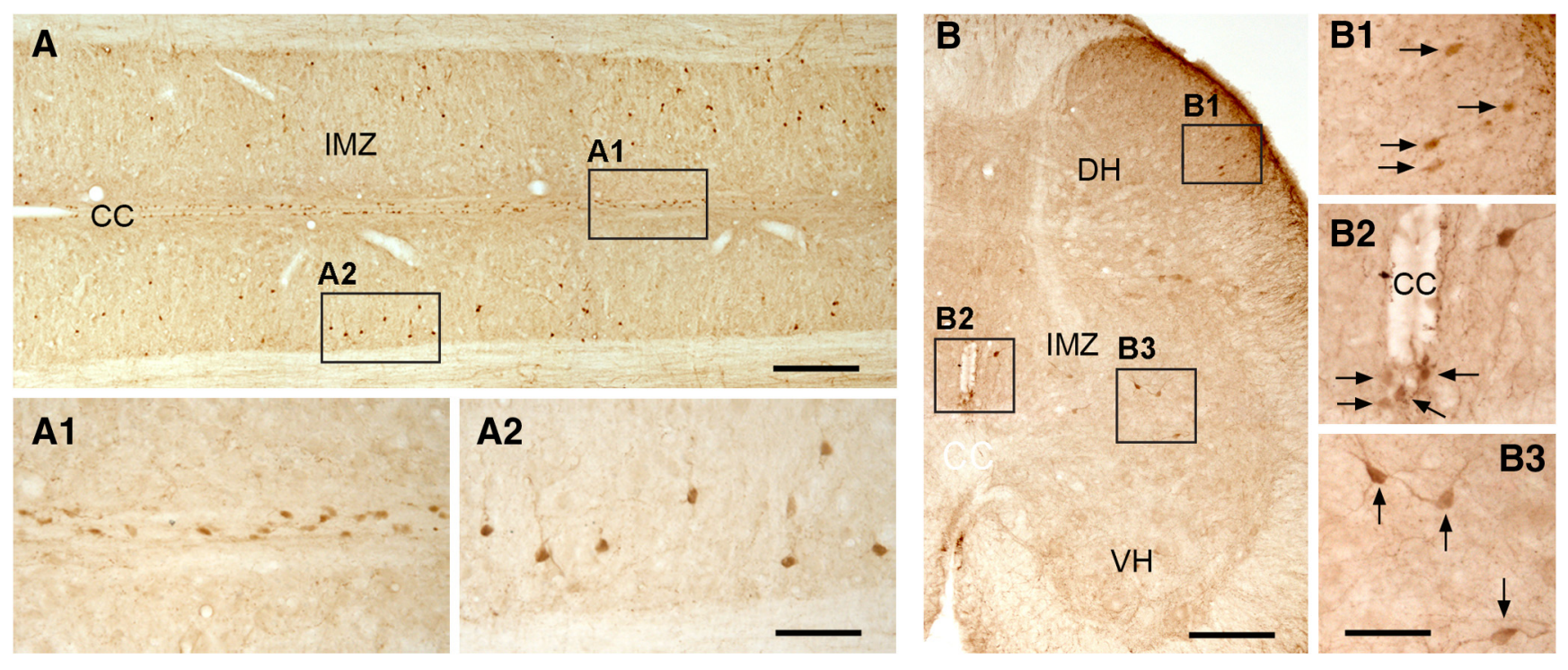

Figure 2. $A A D C$ immunolabeling in normal rat sacrocaudal spinal cord. $A$, A horizontal section from the $S 4 / C$ a1 segment of a normal rat showing $A A D C$-immunopositive cell distribution around the central canal ( $C C ; A 1)$ and in the intermediate zone (IMZ; $A 2) . B, A$ transverse section from the 33 segment of a normal rat showing AADC-immunopositive cell distribution in the dorsal horn (DH; $B 1$ ), around the CC (B2), and in the IMZ (B3). VH, ventral horn. Scale bars: $A, 200 \mu \mathrm{m} ; A 1, A 2,100 \mu \mathrm{m} ; \boldsymbol{B}, 100 \mu \mathrm{m} ; \boldsymbol{B} 1-B 3,50 \mu \mathrm{m}$.

sections were analyzed and the data from normal and spinalized animals were compared.

Analysis of electrophysiological results from in vivo (EMG recordings) and in vitro (ENG recordings) experiments was performed with the Spike2 software. Spontaneous activity was measured as the area under the rectified EMG and normalized to the maximal motor response $\left(M_{\max }\right)$ during stimulation. In recordings of dorsal root-induced reflexes, the spontaneous activity was always calculated from a $1 \mathrm{~s}$ segment of the recording just before stimulation and after the reflex. The LLR duration was calculated after subtraction of the background activity.

As befitting the data being evaluated and with the aid of the SigmaPlot program (Systat Software), statistical analysis was performed using an unpaired or paired $t$ test, Mann-Whitney rank sum test ( $U$ test), or Wilcoxon signed rank test ( $Z$ test). Group-averaged values were expressed as the mean $\pm \mathrm{SD}$, and the significance level was set at $p<0.05$.

\section{Results}

\section{AADC cell distribution in the sacrocaudal spinal cords of normal and spinalized rats}

First, using validated AADC antibodies raised from two different species, we investigated the distribution of AADC cells, especially in the sacrocaudal region, of the normal rat spinal cord. By Western blot, both antibodies display a single band with molecular weight at $50 \mathrm{kDa}$ - the predicted molecular weight for AADC (data not shown). The immunohistochemical results showed that AADC cells are located not only in a region around the central canal, as previously described (Jaeger et al., 1983), but also in the intermediate zone, the dorsal horn, and the white matter (Figs. $2 A, B, 3 A$ ). Because they varied not only in their distribution but also in their morphology and in their expression of neurochemical markers, we undertook a comprehensive study of AADC cells throughout the rat spinal cord. We have prepared a separate manuscript to report this study in detail and do not present our supporting data in this paper. What is important in the present context is that, by double labeling with antibodies to $\mathrm{AADC}$ and another marker, we have found that some AADC cells appear to be mature neurons, whereas others express a marker typical of immature neurons. Thus, AADC cells in the vicinity of the central canal exhibit intense expression of doublecortin but weak expression of $\mathrm{NeuN}$, which is consistent with them possibly being immature neurons. In contrast, the AADC cells located in the intermediate zone and dorsal horn show intense expression of NeuN but weak expression of doublecortin, indicating that they may be mature neurons. Nestin was not expressed by any AADC cells, regardless of their location, indicating that they are not neuronal precursors.

Second, we looked for changes in the distribution and properties of AADC cells following SCI. The results showed that AADC cells in chronically spinalized rats displayed a distribution pattern in the sacrocaudal spinal cord similar to that seen in normal and sham-operated rats (Fig. $3 A-D$ ). To confirm this observation we have performed quantitative analysis of AADC cells in spinal sections from S4 to Cal level from five shamoperated and five $45 \mathrm{~d}$ spinalized rats. As illustrated in Figure $3 E$, when the AADC cell number was calculated in relation to the total volume of the plotted sections, the cell density (cell number per millimeter cubed) in the dorsal horn was $68.9 \%$ higher in the SCI rats than that in the sham-operated rats $(39.7 \pm 10.8$ cells/ $\mathrm{mm}^{3}$ vs $23.5 \pm 8.9$ for SCI and sham-operated rats, respectively). In the intermediate zone, AADC cell density was $21.1 \%$ greater for the SCI rats $(101.4 \pm 19.8$ vs $83.7 \pm 17.7)$. But, in the region of the central canal, the figure for the sham-operated rats was $23 \%$ greater than that for the SCI rats $(46.5 \pm 11.6$ vs $37.8 \pm 15.3)$. Taking all these regions together, the AADC cell density in the SCI rats was $16.3 \%$ greater than in the sham-operated rats $(178.8 \pm 38.3$ vs $153.7 \pm 19.3)$. Although in the dorsal horn, intermediate zone, and whole spinal cord the AADC cells density was higher in the SCI rats than in the sham-operated rats, only in the dorsal horn was there a significant difference between the two groups ( $p<0.05$, unpaired $t$ test). Comparisons of Figure $3 A$ with $B$ and $C$ with $D$ shows that, at matched segmental levels, spinal cord sections from SCI rats were much smaller than those from normal or sham-operated rats. Although the gray matter was reduced to some extent, this difference was largely due to the atrophy of the white matter in the SCI rats (Anelli et al., 2007). Thus, when the AADC cell density was calculated only for the gray matter, no significant 
A Normal rat - horizontal (S1 - Ca3)

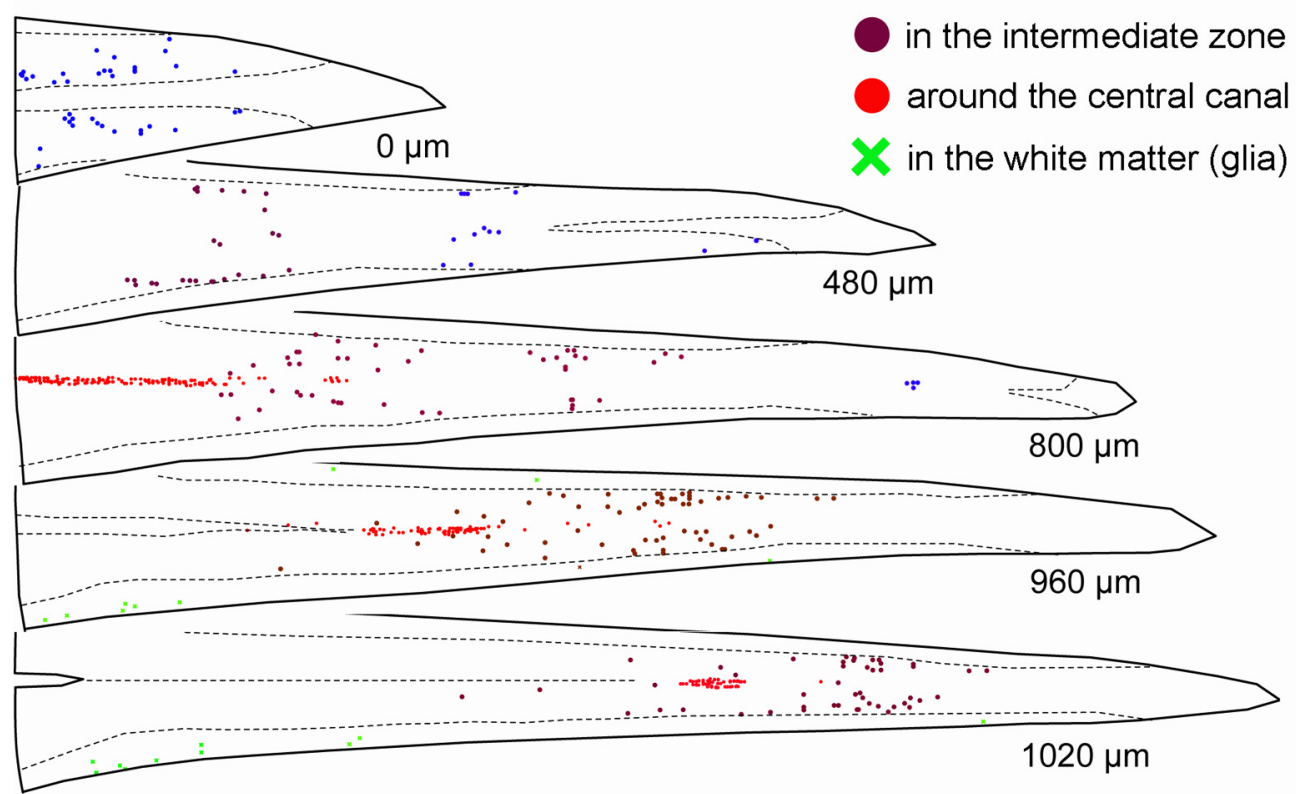

AADC cells in the dorsal horn

in the intermediate zone

(1)

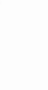
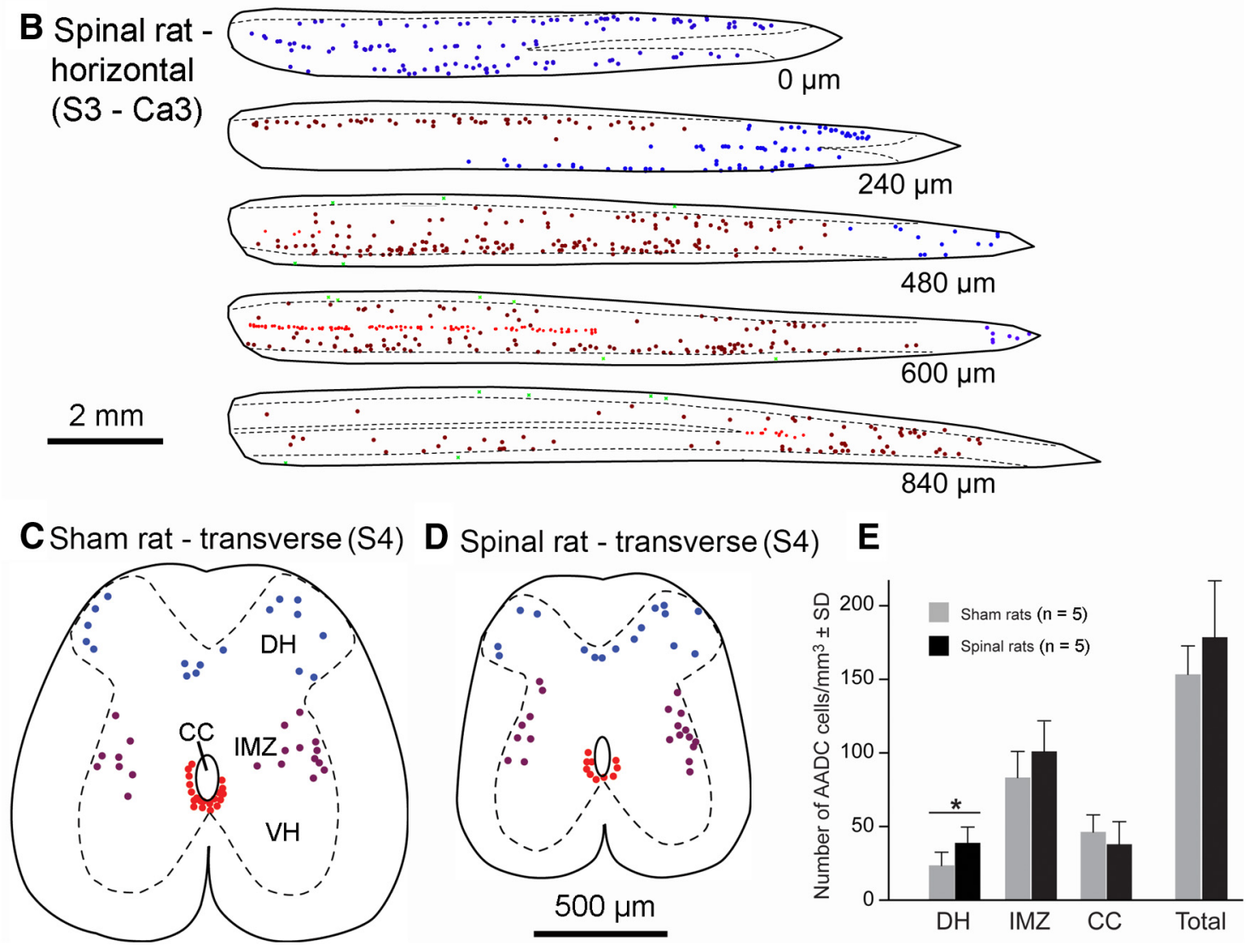

Figure 3. Plots of the $A A D C$ cells in the sacrocaudal spinal cord from normal control and spinalized rats. $A$, Plots of selected sections from a normal rat showing $A A D C$ cell distribution in different areas of the spinal cord from S1 to Ca3 segments. B, Plots of selected sections from a $79 \mathrm{~d}$ spinalized rat showing AADC cell distribution in the spinal cord from S3 to Ca3 segments. Due to shrinkage of the spinal cord in the spinalized rat, the spinal cord below the lesion assumed a rod-like shape rather than the conical shape typical of the normal rat, and more $A A D C$ neurons were located in single sections. The number at the right below each section indicates the distance to the first section. $C, D, A A D C$ cell distribution in transverse sections in a $45 \mathrm{~d}$ sham-operated (sham, $\boldsymbol{C}$ ) and a $45 \mathrm{~d}$ spinalized (spinal, D) rat plotted from five sacral 4 (S4) transverse sections with an average intersection distance of $400 \mu \mathrm{m}$. Locations of AADC cells are indicated by blue dots in the dorsal horn (DH), purple dots in the intermediate zone (IMZ), red dots near the central canal (CC), and green crosses in the white matter (glia). VH, ventral horn. $E$, Quantitative data showing AADC cell density in different regions of the spinal gray matter from a group of $45 \mathrm{~d}$ sham and spinalized rats. In the DH and IMZ, the density of the AADC cells was greater in the spinalized rats than in the sham rats, but the difference was statistically significant only in the DH $\left({ }^{*} p<0.05\right.$, unpaired $t$ test). AADC cell density in the vicinity of the $(C$ was similar for the two groups, and, although the cumulative density of AADC cells ("Total" in $\boldsymbol{E}$ ) was greater in the spinalized rats, the difference between the two groups was not statistically significant. Scale bars: (in $B) A, B, 2 \mathrm{~mm}$; (in C) C, D, $500 \mu \mathrm{m}$. 

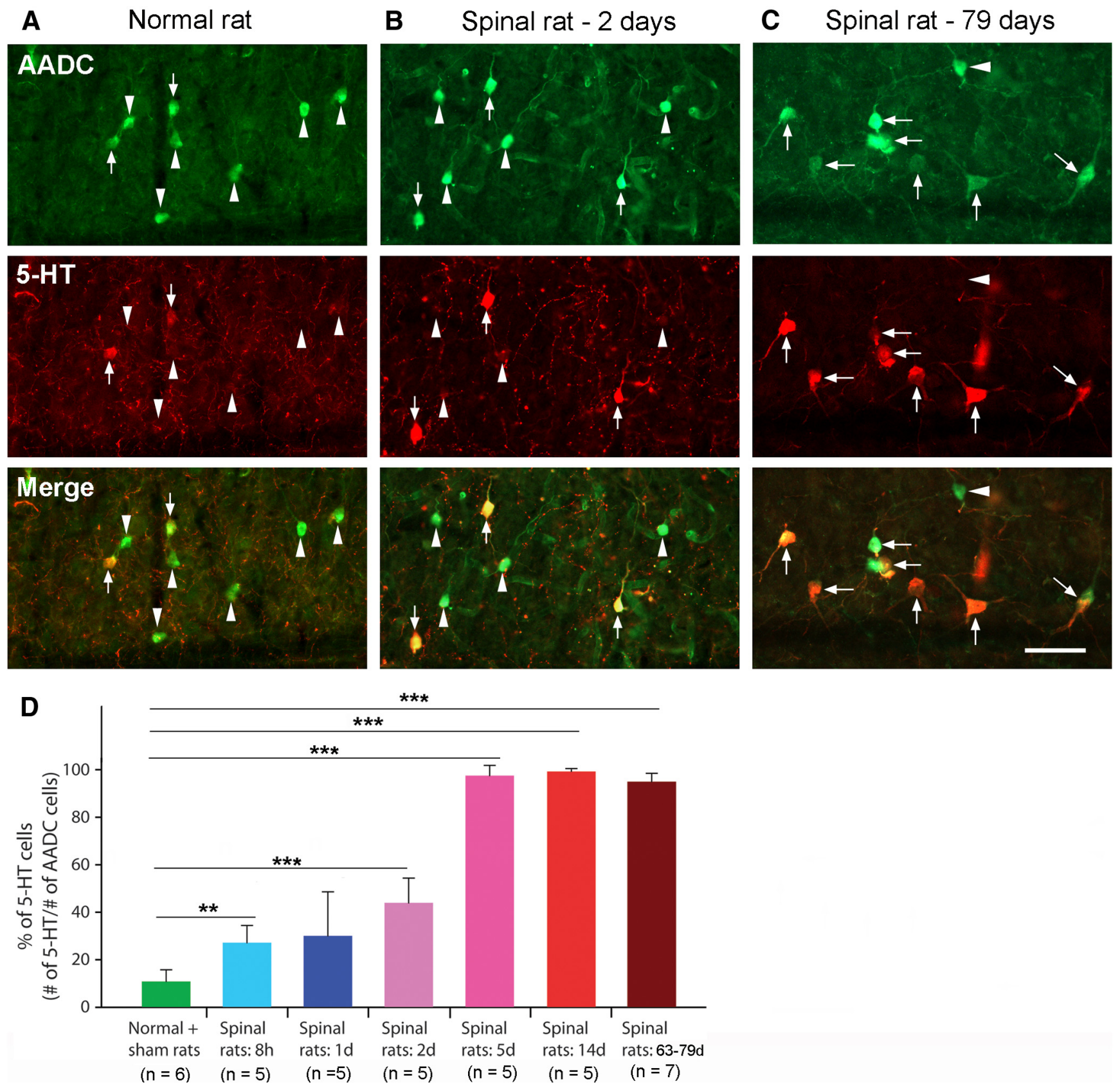

Figure 4. 5-HT expression in AADC cells in normal/sham-operated (sham) and spinalized rat spinal cords after intraperitoneal injection of 5 -HTP (100 mg/kg). $A$, In a normal control rat, only a few AADC cells became 5-HT positive (arrows); most were 5-HT negative (arrowheads). $\boldsymbol{B}$, In a $2 \mathrm{~d}$ spinalized rat, a larger proportion of AADC cells were induced to express 5 -HT. C, In a $79 \mathrm{~d}$ spinalized rat, almost all of the AADC cells expressed 5-HT (arrows). D, Group data showing the time course of 5-HT expression in AADC cells in normal (including sham) and spinalized rats at six different time intervals. After 5-HTP application in normal and sham rats ( 3 normal and 3 sham), only $10.8 \pm 4.9 \%$ of the AADC cells became 5 -HT positive. The values for the spinalized groups were as follows: $8 \mathrm{~h}, 27.2 \pm 7.2 \% ; 1 \mathrm{~d}, 30.1 \pm 18.5 \% ; 2 \mathrm{~d}, 44.0 \pm 10.4 \% ; 5 \mathrm{~d}, 97.5 \pm 4.3 \% ; 14 \mathrm{~d}, 99.5 \pm 0.4 \% ;$ and $>60 \mathrm{~d}, 95.0 \pm 3.5 \%$. Except for $1 \mathrm{~d}$ group, for all spinalized groups, $5-\mathrm{HT}$ expression by AADC cells was significantly greater than that in the normal + sham group $\left({ }^{* *} p<0.01\right.$, ${ }^{* *} p<0.001$, t test or $U$ test). Scale bar, (in $\left.\boldsymbol{C}\right) \boldsymbol{A}-\boldsymbol{C}, 50 \mu \mathrm{m}$.

difference was detected in any of these regions between the sham-operated and SCI rats (data not shown).

\section{AADC cells increase their ability to produce 5-HT after SCI}

To investigate whether a complete spinal transection induces a change in the AADC cell phenotype, we injected 5-HTP intraperitoneally in normal control, sham-operated, and spinalized rats at several postoperative intervals. In normal control $(n=3)$ and sham-operated $(n=3)$ rats, the proportion of AADC cells that became 5 -HT positive was quite similar (10.1 \pm 7.5 and $11.6 \pm 1.8 \%$, respectively). The data from these two groups were pooled to yield the result shown in Figure 4, $A$ and $D$, that $10.8 \pm$ $4.9 \%$ of AADC cells was capable of converting 5 -HTP to 5 -HT. In contrast, AADC cells in the sacrocaudal spinal cords of spinalized rats exhibited dramatically increased expression of 5-HT. Already at $8 \mathrm{~h}$ after spinalization $27.2 \pm 7.2 \%$ of AADC cells were 5 -HT positive ( $p<0.01$, unpaired $t$ test). Thereafter, 5-HT expression gradually increased with time. At $24 \mathrm{~h}$ after SCI, $30.0 \pm$ $18.5 \%$ of the AADC cells were 5 -HT immunopositive; at $2 \mathrm{~d}$ the value was $44.0 \pm 10.4 \%$ (Fig. $4 B, D$ ). At $\sim 5 \mathrm{~d}$ post-SCI, a plateau level was reached, the proportions of AADC cells that were 5-HT immunopositive at 5,14, and $>60 \mathrm{~d}$ were, respectively, $97.5 \pm$ 


\section{A1-A3 Normal rat without 5-HTP application}
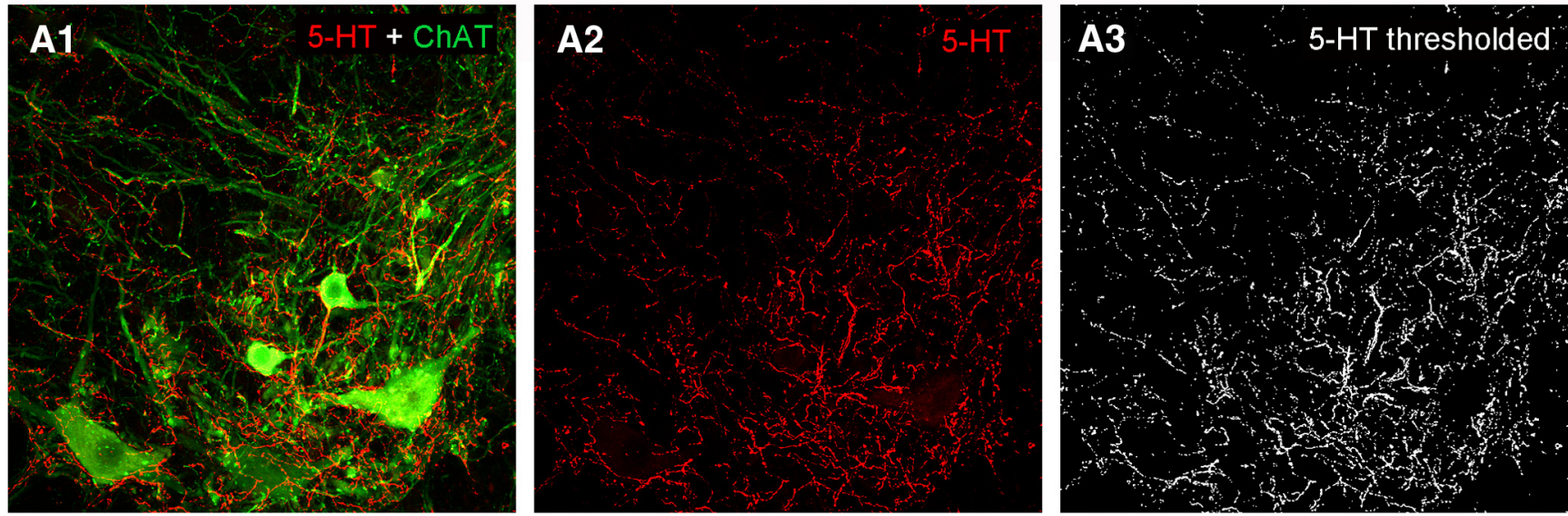

\section{B1-D Spinal rats after carbidopa and 5-HTP application}
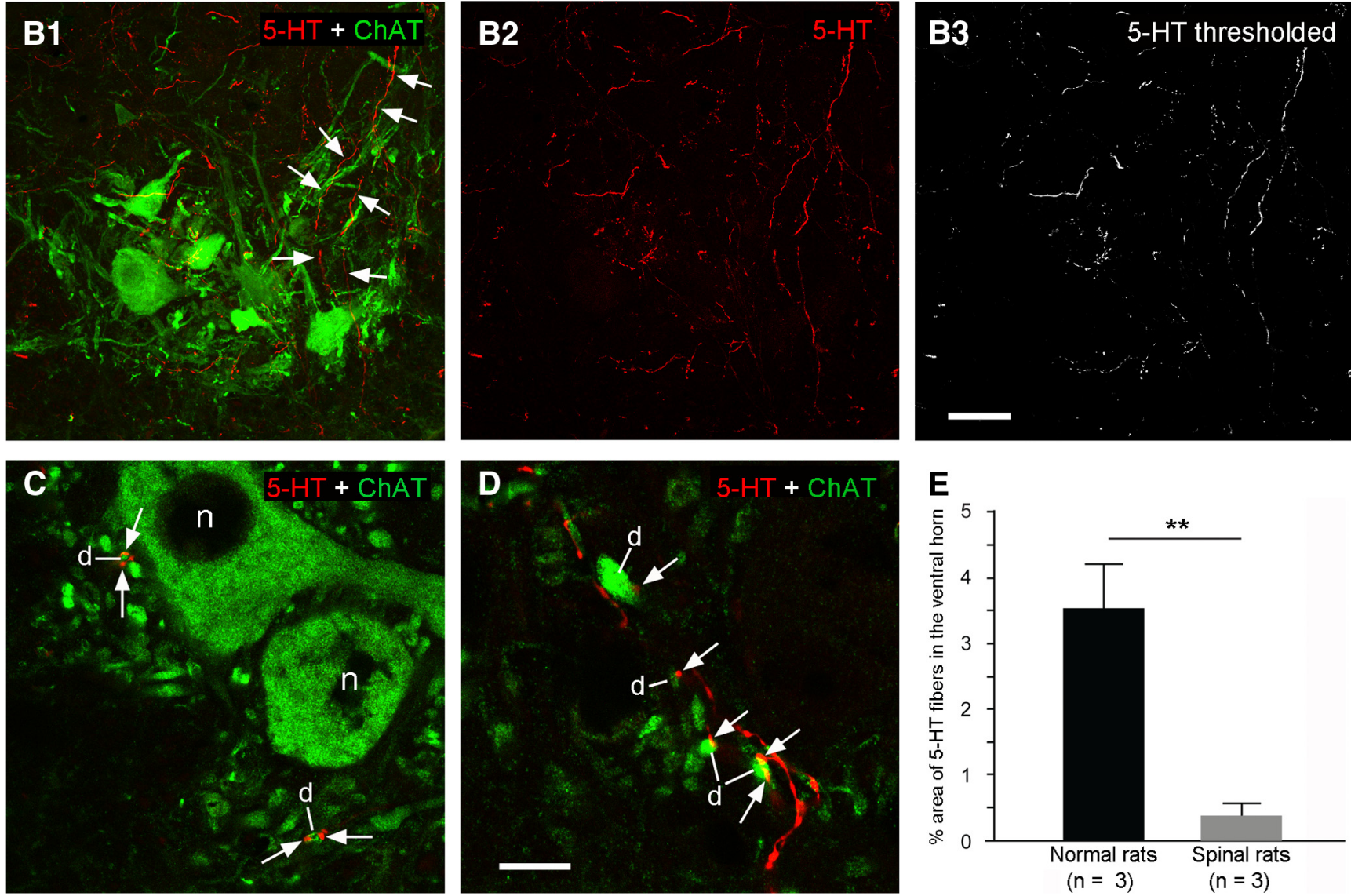

Figure 5. 5-HTP-induced 5-HT-immunopositive fibers from AADC cells innervate motoneurons in the ventral horn. $\boldsymbol{A} 1, \mathrm{In}$ a normal rat, 5 -HT fibers were densely distributed in the ventral horn around ChAT-labeled motoneuronal somata and dendrites. A2, Only 5-HT immunoreactivity is shown in the selected region. A3, 5-HT-immunopositive components above the threshold after thresholding in (A2). B1-D, Following application of carbidopa (20 mg/kg, i.p.) plus 5 -HTP (100 mg/kg, i.p.), 5 -HT-immunopositive fibers were clearly seen in the ventral horn motoneuron region in a 75 d spinalized rat. B1-B3, Same format as A1-A3.5-HT-immunopositive fibers extend from the intermediate zone into the ventral horn (arrows in B1). All sections are transverse through S4, and in each dorsal is upward and lateral is to the left. C, D, 5-HT-immunopositive fiber terminals/varicosities were often closely apposed to ChAT-immunopositive motoneuron dendrites (d) in the ventral horn (arrows) but rarely appeared next to motoneuron somata (e.g., $\mathrm{n}$ in $\mathbf{C}$. Scale bars: (in $\boldsymbol{B} 3$ ) $\boldsymbol{A} \mathbf{1}-\boldsymbol{B} 3,50 \mu \mathrm{m}$; (in $\boldsymbol{D}$ ), $\boldsymbol{C}, \boldsymbol{D}, 10 \mu \mathrm{m}$. E, Group data show 5-HT-immunopositive fiber density in the ventral horns of three normal rats without 5 -HTP application and of three $75 \mathrm{~d}$ spinalized rats following 5 -HTP application. The 5 -HT fiber density in the normal rats is 9.3 -fold greater than in the spinalized rats. This difference is significant $\left({ }^{* *} p<0.01, t\right.$ test $)$.

$4.3,99.5 \pm 0.4$, and $95.0 \pm 3.5 \%$ (Fig. $4 C, D$ ). In the chronically spinalized rats AADC-immunopositive fibers could be observed not only in the dorsal horn, intermediate zone, and the region around the central canal, but also in the ventral horn motoneuron region. To maximally label 5-HT-immunopositive AADC fibers in the spinal cord, we injected 5-HTP plus carbidopa in three SCI rats and compared the 5-HT fiber density with that from three normal rats that were not injected with 5-HTP. As illustrated in Figure 5, B1-B3, there were many 5-HT-positive fibers in the ventral motoneuron region in the SCI rats although 
the density was much less than that in the normal rats (Fig. 5A1B3). 5-HT fiber terminals or varicosities were often apposed to ChAT-labeled dendrite-like profiles, but seldom to motoneuron somata (Fig. 5C,D). Quantitative data showed that, in normal rats, 5-HT-immunopositive fibers occupied, on average, $3.5 \pm$ $0.7 \%$ (4.0, 3.8, and $2.8 \%$ for the three rats, respectively) of the analyzed ventral horn area, whereas in SCI rats the value was $0.4 \pm 0.2 \%(0.5,0.3$, and $0.2 \%$ for the three rats, respectively). There was a significant difference between the two groups ( $p=$ 0.001 , unpaired $t$ test). These results indicate that if all of the AADC cells were available to produce $5-\mathrm{HT}$, they could provide $\sim 11.4 \%$ of the normal 5 -HT content of the ventral horn motoneuron region.

\section{5-HT produced in the AADC cells below the lesion increased the excitability of motoneurons}

The fact that AADC cells become 5-HT immunopositive after SCI raises questions as to whether they can become functionally active and release 5-HT and whether they are causally related to the hyperexcitability of motoneurons (and interneurons) and thus to the development of tail spasticity. We therefore assessed activity of the motoneurons to the tail muscles both in vivo (Fig. 6) and in vitro (Fig. 7).

When spinalized rats were given an intraperitoneal injection of 5-HTP, the spontaneous tail EMG activity was dramatically enhanced at first, but it declined over time (Fig. 6B1). Thus, in the first 5 min after 5-HTP application, spontaneous EMG activity was 8.0 times greater than in the first $5 \mathrm{~min}$ of baseline recording; whereas over the entire 20 min recording session, EMG activity was only 3.7 times greater than baseline (Fig. 6B2). Compared with baseline activity, the EMG activity increase for both recording intervals was statistically significant ( $p<0.05$ for both comparisons, $Z$ test). The difference between the two recording intervals following 5-HTP injection was also significant $(p<$ $0.05, Z$ test), but this gradually diminishing effect is probably due to motoneuron adaptation. However, when the AADC enzyme was blocked with benserazide $(800 \mathrm{mg} / \mathrm{kg}$, i.p.), a subsequent 5-HTP injection did not enhance tail EMG activity (Fig. 6C1,C2). Rather, the spontaneous EMG activity was $14.6 \%$ lower after benserazide application and $32.9 \%$ lower after a subsequent 5-HTP injection compared with the baseline level, but none of these reached a significance level. A similar effect was achieved when benserazide was intrathecally injected, confirming that the blockade by benserazide was due to the action in the spinal cord itself (Fig. 6D1,D2). Immunohistochemical analysis of spinal cords from the same rats showed that few or none of the AADC cells were 5-HT immunopositive (range: $0-16.1 \%$; average: $2.6 \pm 6.8 \% ; n=10$ ) following 5 -HTP injection, whereas the immunoreactivity of AADC cells was unaffected (Fig. $6 E$ ), indicating effectiveness in inhibiting the AADC's ability to convert 5-HTP to 5-HT. To investigate which 5-HT receptors mediate the increased excitability of motoneurons, we intraperitoneally injected cyproheptadine (a 5-HT2 receptor antagonist) following 5 -HTP administration ( $n=7$ rats). The results showed that cyproheptadine could completely block the effects of 5-HTP (data not shown).

We used in vitro electrophysiological recording techniques to further confirm that $5-\mathrm{HT}$ is produced by AADC cells in the spinal cord below the lesion (Fig. 7). Addition of graded concentrations $(0.005-0.1 \mathrm{~mm})$ of 5-HTP to the bathing solution resulted in a progressive increase in spontaneous ENG activity in the ventral roots (Fig. 7A). This dose-dependent effect was statistically significant at concentrations of $0.01,0.05$, and $0.1 \mathrm{mM}$
5-HTP, but not at $0.02 \mathrm{~mm}$ due to the highly variable results at this concentration (paired $t$ test or $Z$ test; for respective $p$ values, see Fig. $7 \mathrm{~A}$ legend). We also recorded dorsal root-induced LLRs (Fig. 7B1; which cause spasms in the in vivo model; Bennett et al., 2004) following 5-HTP bath application. In six of seven preparations, a concentration of $0.01 \mathrm{~mm} 5$-HTP in the aCSF bath increased the LLR duration by an average of $94.6 \%(n=7$; Fig. 7B2). Similarly, three of four preparations subjected to $0.05 \mathrm{~mm}$ 5-HTP showed increased LLR durations, with an average increase of $292.8 \%(n=4$; Fig. $7 B 2)$. Although these findings are consistent with the statistically significant results of other experiments reported here, large data variations in small sample sizes kept them from attaining statistical significance. Finally, we investigated the effects of benserazide on the dorsal root-induced LLRs. When benserazide $(0.3-0.5 \mathrm{~mm})$ was added to the bath solution before 5-HTP addition $(0.05 \mathrm{~mm})$, no significant increase in the spontaneous ENG responses could be detected ( $n=10$; Fig. $7 C$; $p>0.05, Z$ test). However, when LLR was recorded after benserazide bath application, in six of seven rats LLRs were reduced by an average of $24.2 \%$ ( $n=7$; Fig. $7 D 1, D 2)$. Probably because of large data variations the reduction in LLRs following benserazide application did not reach significance ( $p=0.29$, paired $t$ test). However, most importantly, the subsequent 5-HTP application did not increase or prolong the LLR (actually the amplitude was further decreased, perhaps due to an increasing effect of benserazide with time). Immunohistochemical data from the in vitro spinal cords examined showed that almost all of the AADC cells in the spinal cord became 5-HT immunopositive with 0.05 or 0.1 mM 5-HTP in the aCSF solution (range: $82.2-98.5 \%$; average: $94.4 \pm 5.7 \% ; n=7$; Fig. $7 E$ ), but when benserazide was added before 5-HTP, few or none of the AADC cells became 5-HT positive (range: $0-3.8 \%$; average: $0.8 \pm 1.4 \% ; n=9$; Fig. $7 F$ ). These in vitro experiments thus confirmed that $5-\mathrm{HT}$ synthesized in the spinal cord below the lesion might underlie the hyperexcitability of motoneurons and, thus, the increases noted in spontaneous activity and dorsal root-induced LLRs.

\section{Possible mechanism for the phenotypic change of AADC cells following SCI}

AADC and 5-HT double-immunolabeling experiments revealed that, in normal rats, the AADC cells of all spinal cord regions are often juxtaposed to many 5-HT fiber varicosities (Fig. 8A-C). The absence of brainstem-derived 5-HT fibers in spinalized rats (Fig. $8 D$ ) led us to hypothesize that one mechanism for the increased ability of AADC cells to convert 5-HTP to 5-HT following spinal transection might be their release from suppression by the raphe-spinal serotonergic innervation. Such a release from suppression could be caused by the loss of activation of the 5-HT1 receptors from the raphe-spinal serotonergic innervation (Branchereau et al., 2002), which most likely involves 5-HT1B receptors, although 5-HT1A receptors cannot be excluded (Brown et al., 1988; Murphy and Zemlan, 1988). Thus, we decided to activate 5-HT1B receptor in spinalized rats by applying 5-HT1B agonist CP94253 and to inhibit this receptor in normal rats by applying 5-HT1B antagonist SB216641 to establish whether these manipulations would change 5-HT expressions in these two groups of rats following 5-HTP application. Spontaneous tail EMG responses were recorded in SCI rats to examine the physiological effect of the 5-HT1B agonist. As shown in Figure 9A, after CP94253 subcutaneous injection, the EMG response within a 20 min interval was still greatly increased following 5-HTP application compared with the baseline value before 5-HTP application (6.0 \pm 3.1 time of the baseline level). Com- 
A In vivo rat tail EMG recording setup

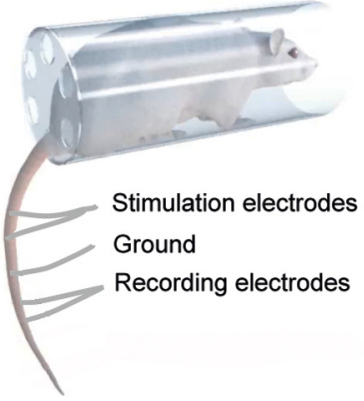

C1 Bens (i.p.) blocked the effect of 5-HTP (i.p.) - raw spontaneous tail EMG activity from the same rat

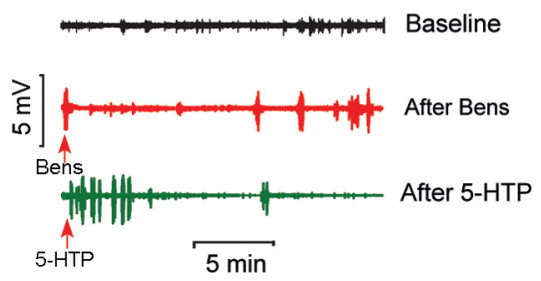

D1 Group data of spontaneous tail EMG activity after aCSF i.t and 5-HTP i.p. application from the same rats

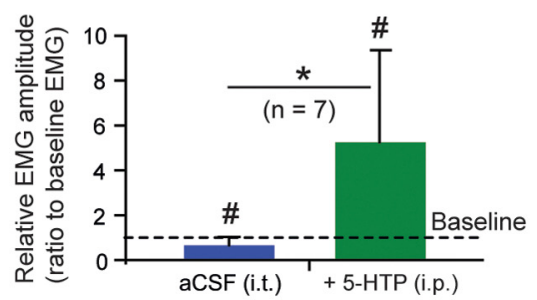

B1

Effect of 5-HTP (i.p.) on spontaneous tail EMG activity - raw EMG from the same rat

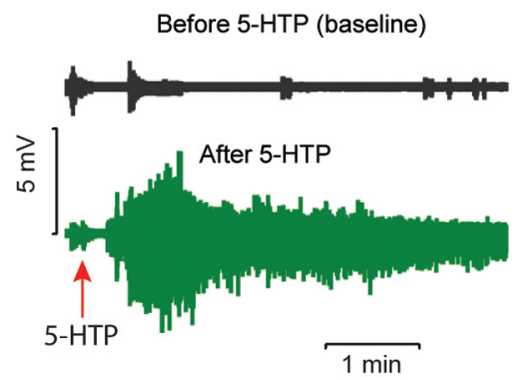

C2

Group data of spontaneous tail EMG activity after Bens i.p. and 5-HTP i.p. application from same rats

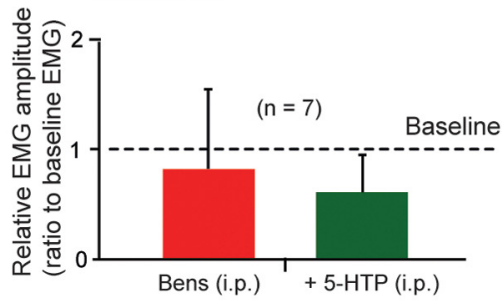

D2

Group data of spontaneous tail EMG activity after Bens i.t. and 5-HTP i.p. application from same rats

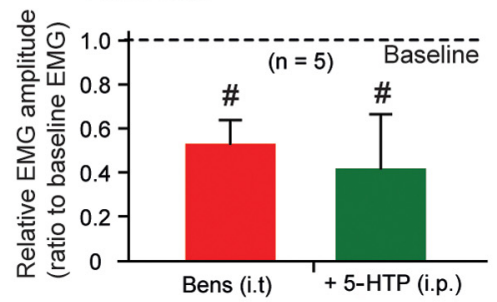

B2 Group data of spontaneous tail EMG activity changes following 5-HTP i.p. application from the same rats

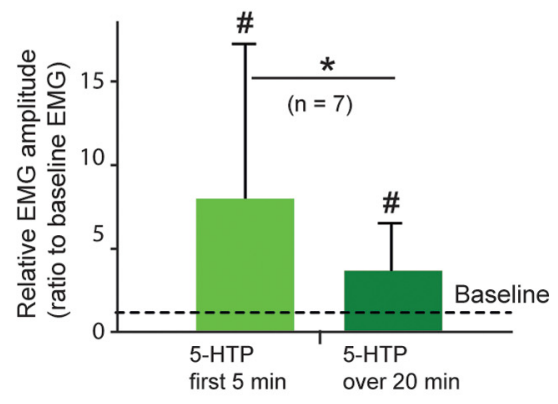

E

$5-\mathrm{HT}$ was not expressed in AADC cells following 5-HTP (i.p.) when AADC was blocked by Bens (i.t.)
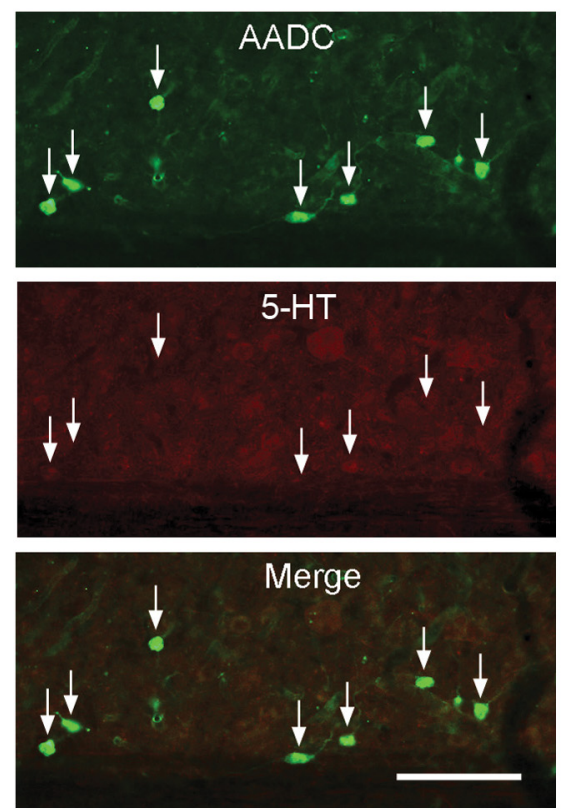

Figure 6. In vivo electrophysiological experiments show that 5-HTP increases spinal motoneuron excitability in chronically spinalized rats. $A$, Setup of in vivo electrophysiology recording of rat tail muscle EMG. B1, Raw spontaneous tail EMGs from a $63 \mathrm{~d}$ spinalized rat, demonstrating the baseline activity before (upper trace) and after 5-HTP application (i.p., $100 \mathrm{mg} / \mathrm{kg}$; lower trace). Spontaneous tail EMGs were dramatically increased following 5-HTP administration. B2, Group data show that, compared with the baseline values in the same rats, the average spontaneous EMG activity increased 8.0 -fold over the first $5 \mathrm{~min}$ and 3.7 -fold over the entire $20 \mathrm{~min}$ duration of the recording session ( $n=7,63-79 \mathrm{~d}$ spinalized rats). EMG activity over both post-5-HTP time intervals was significantly higher than the baseline level ( $\# p<0.05, Z$ test). There was also a significant difference between the shorter and longer recording intervals $\left({ }^{*} p<0.05, Z\right.$ test), indicating that 5-HTP effect was transient. C1, Raw spontaneous EMGs (from a $63 \mathrm{~d}$ spinalized rat) at baseline (black trace), after intraperitoneal injection of benserazide hydrochloride (Bens; $800 \mathrm{mg} / \mathrm{kg}$; red trace) and after subsequent 5-HTP intraperitoneal injections ( $100 \mathrm{mg} / \mathrm{kg}$; green trace). C2, Group data (57-80 d postspinalization) show that Bens pretreatment blocked the stimulatory effect of 5-HTP (compare red bar and green bar, $p=0.30$, paired $t$ test). Bens intraperitoneal injection reduced the EMG activity by $14.6 \%$, compared with baseline spontaneous EMG activity, but this result was not statistically significant ( $p=0.32$, paired $t$ test). Injection of 5 -HTP did not increase the average spontaneous EMG activity. D1, D2, Group data (82-117 d post spinalization) show the same AADC blocking effect when Bens was injected intrathecally (i.t.). D1, In the control spinalized rats, after aCSF was injected ( $20-25 \mu$ l, i.t.), the spontaneous EMG was somewhat reduced (34.4\% lower than the baseline EMG, \#p $<0.05, Z$ test), probably due to the motoneuron adaptation after prolonged recording. A subsequent 5-HTP (100 mg/kg, i.p.) injection induced a 5.3-fold increase in spontaneous EMG activity (\#p $<0.05, Z$ test) and an 8.0-fold increase compared with the EMG after an aCSF intrathecal injection $\left({ }^{*} p<0.05, Z\right.$ test). D2, In another group of animals, when Bens was intrathecally injected ( $0.3-0.5 \mathrm{~mm}$, in $20-25 \mu \mathrm{laCSF}$ ) the spontaneous EMG response decreased by $47.5 \%$ ( $52.5 \pm 10.5 \%$ of baseline EMG level). Subsequent $5-\mathrm{HTP}$ ( $100 \mathrm{mg} / \mathrm{kg}$, i.p.) injection did not increase the spontaneous EMG activity in the same rats ( $p=0.23$, paired $t$ test). The difference was significant when compared with baseline both in Bens and Bens plus 5 -HTP groups (\#p $<$ 0.05 , paired $t$ test). $E$, AADC and $5-H T$ immunostaining of a horizontal spinal cord section through $S 4$ of a rat that was killed on postoperative day 82 shows no 5 -HT double labeling of AADC cells in the intermediate gray matter after Bens intrathecally (0.5 mм in $20 \mu \mathrm{laCSF})$ and subsequent 5 -HTP intraperitoneally $(100 \mathrm{mg} / \mathrm{kg})$ injections. Scale bar, $100 \mu \mathrm{m}$.

pared with the saline control rats, in which the EMG response was $8.8 \pm 11.2$ time of the baseline value, the increase was still $46.7 \%$ lower, although the difference was not significant $(p=0.70, U$ test). We have examined 5-HT immunolabeling in CP94253injected rats and we observed that fewer AADC cells appeared
5-HT immunopositive in these rats than in the saline control rats receiving the same amount of 5-HTP (Fig. 9D, compare Fig. 4C, which is similar to the saline control SCI rat). In CP94253injected rats, 5-HT-immunopositive AADC cell expression was reduced by $29.0 \%$ compared with the saline control group (Fig. 
A Increased ENG spontaneous activity following 5 -HTP bath application

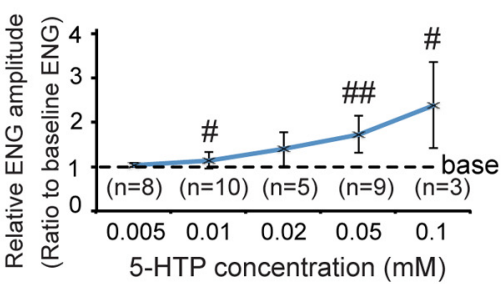

C Group data show no increase of spontaneous ENG activity after Bens and 5-HTP bath application

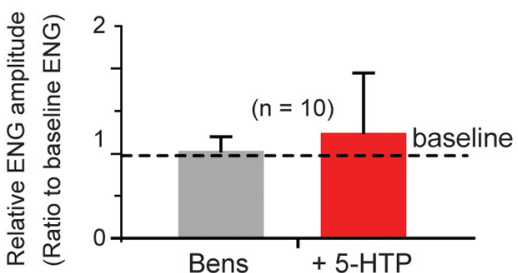

E AADC cells became 5-HTimmunopositive follwoing 5-HTP bath application
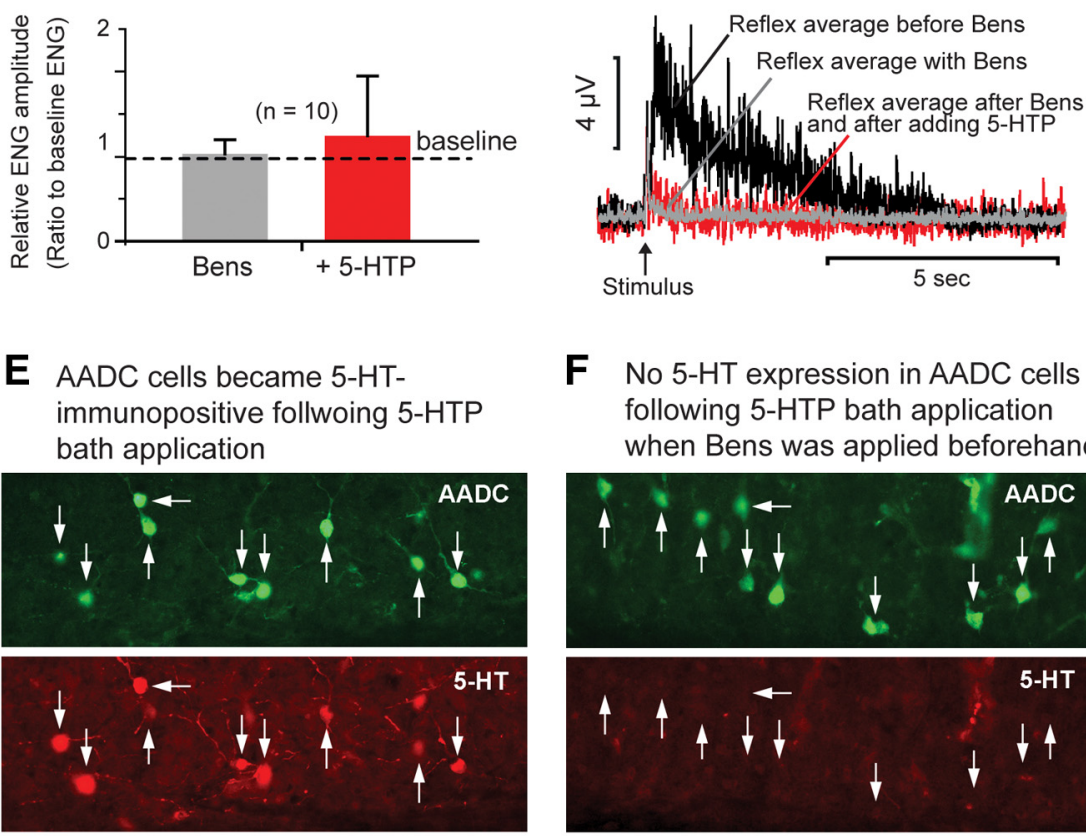

F No 5-HT expression in AADC cells following 5-HTP bath application when Bens was applied beforehand
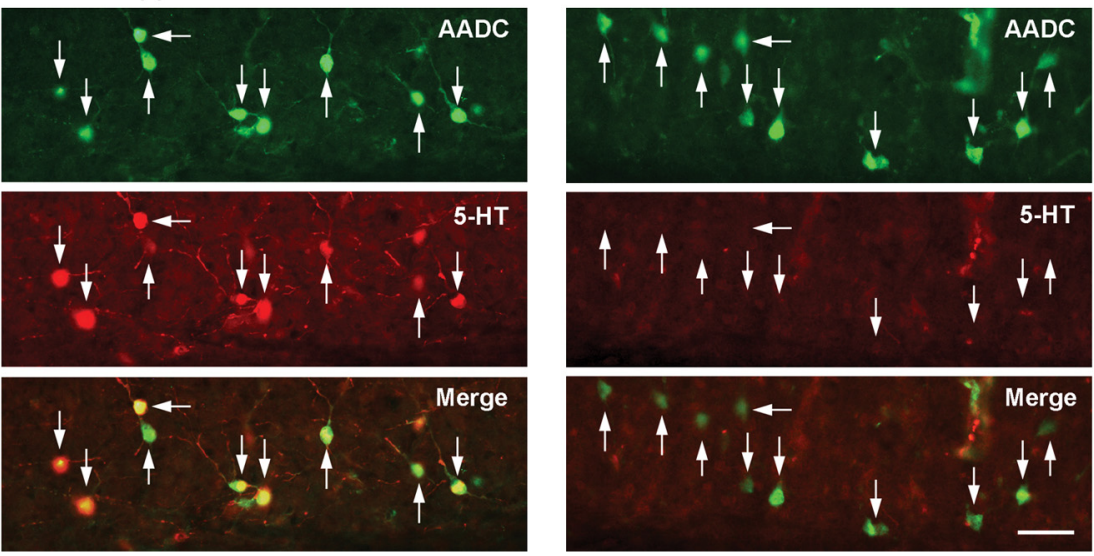

B2

Group data show increase of DR stimulus-induced LLRs after 5-HTP bath application

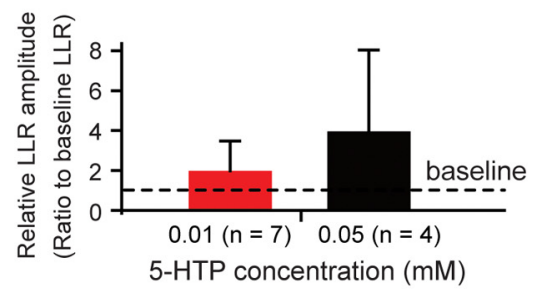

D2

Group data show decrease of DR stimulus-induced LLRs after Bens bath application

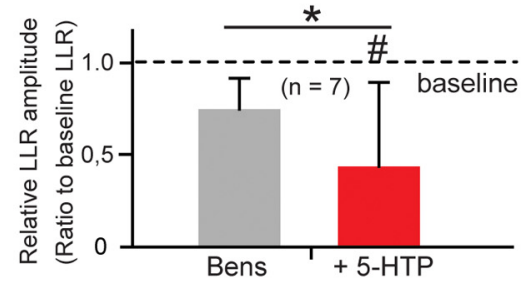

G In vitro experiment setup

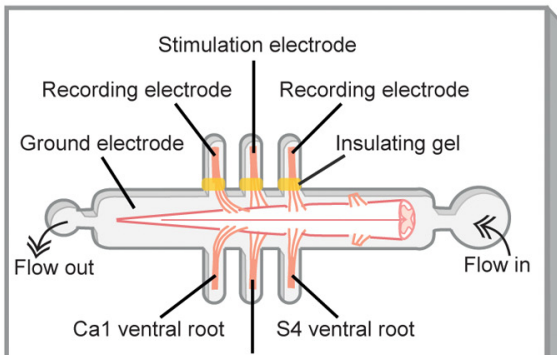

Ca1 dorsal root

Figure 7. In vitro electrophysiological experiments show that 5-HTP increases spinal motoneuron excitability in chronically spinalized rats. $A$, Line graph illustrates the progressive increase in spontaneous ENG activity with increasing concentrations of 5-HTP in the bath solution. Comparison of the ENG amplitude was between baseline value and that after 5 -HTP application in each group (\#p $<0.05$, \#\#p <0.01, paired $t$ test or Z test). B1, Rectified ENGs show how the dorsal root (DR) stimulus-induced LLRs increased with increasing concentrations of 5-HTP in a $71 \mathrm{~d}$ spinalized rat. B2, Group data show a dramatic increase of DR stimulus-induced LLRs after 5 -HTP bath application compared with the baseline level. At $0.01 \mathrm{~mm}$ concentration the LLR increase was $94.6 \%$, whereas at $0.05 \mathrm{~mm}$ the increase was $292.8 \%$. However, due to the large variations between the cases, the differences were not statistically significant $(p>0.05$, for comparisons with the baseline in each treatment group, paired $t$ test). C, Group data (53-126 d spinalized rats) show no increase in LLRs following 5-HTP bath application ( 0.05 mm) when the AADC enzyme was blocked by benserazide hydrochloride (Bens; $0.3-0.5 \mathrm{mM}$ ). There was no significant difference in LLR duration after the application of Bens alone or following 5-HTP application compared with the baseline results for either treatment group; there was no significant difference between the two groups ( $p>0.05$ for all comparisons, $Z$ test). D1, Rectified ENGs show that Bens bath application ( $0.3 \mathrm{~mm}$ ) reduced the DR stimulus-induced LLRs and also blocked the effect of 5-HTP $(0.05 \mathrm{~mm})$ in increasing the amplitude of LLRs in a $122 \mathrm{~d}$ spinalized rat. D2, Group data show the reduction in the amplitude of DR stimulus-induced LLRs following bath application of Bens $(0.3-0.5 \mathrm{~mm})$. On average, the LLR amplitude was $24.2 \%$ lower than the baseline level after Bens application, but this reduction did not reach significance. The subsequent $5-H T P(0.05 \mathrm{~mm}$ ) application did not increase the LLR (actually the amplitude was further decreased, probably due to an increasing effect of benserazide with time, and this decrease reached significance; $p<0.05$, paired t test). $E$, AADC and 5-HT immunolabeling of an 54 spinal cord section from an $81 \mathrm{~d}$ spinalized rat following $0.05 \mathrm{~mm} 5$-HTP application in aCSF without prior Bens application. Note that all of the AADC cells were double labeled with 5-HT. F, AADC and 5-HT immunolabeling of an S4 spinal cord section from a $58 \mathrm{~d}$ spinalized rat following 0.05 mм 5-HTP application in the aCSF with prior Bens $(0.3 \mathrm{~mm})$ treatment. Note that no AADC cells show 5-HT immunoreactivity. Scale bar, (in $\boldsymbol{F}) \boldsymbol{E}, \boldsymbol{F}, 50 \mu \mathrm{m}$. $\boldsymbol{G}$, Schematic illustration of the in vitro recording setup with the sacrocaudal spinal cord ventral side up in the recording chamber.

$9 B)$. Thus, the percentage of AADC cells that were also 5-HT immunopositive was $92.6 \pm 5.1 \%$ in the saline control group, and $65.7 \pm 7.5 \%$ in 5 -HT1B agonist group. The difference between these two groups was significant $(p<0.001$, unpaired $t$ test).
In the normal rats in which 5-HT1B antagonist SB216641 was subcutaneously injected, the 5-HT-immunopositive AADC cells were increased compared with the control group with or without saline injection following 5-HTP injection (Fig. 9E, compare Fig. 4A). In SB216641-injected rats, 5-HT-immunopositive AADC 


\section{A Normal rat - dorsal horn}

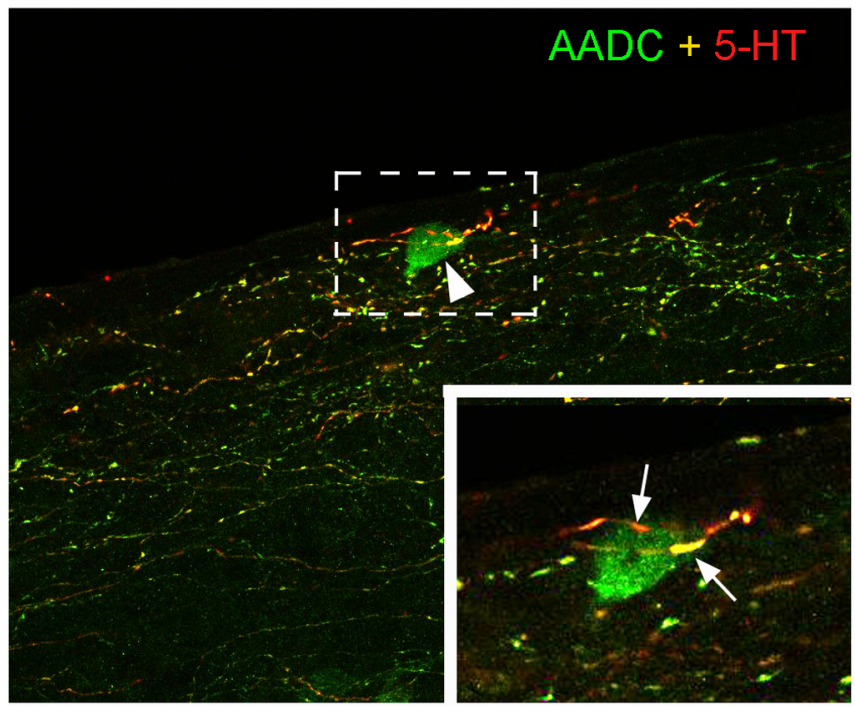

C Normal rat - around central canal

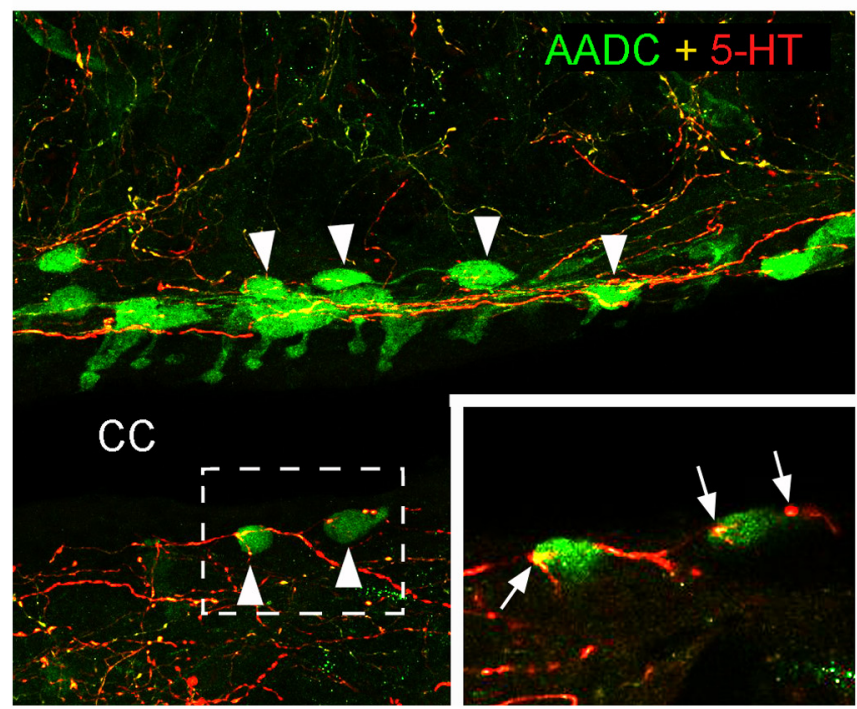

\section{B Normal rat - intermediate zone}

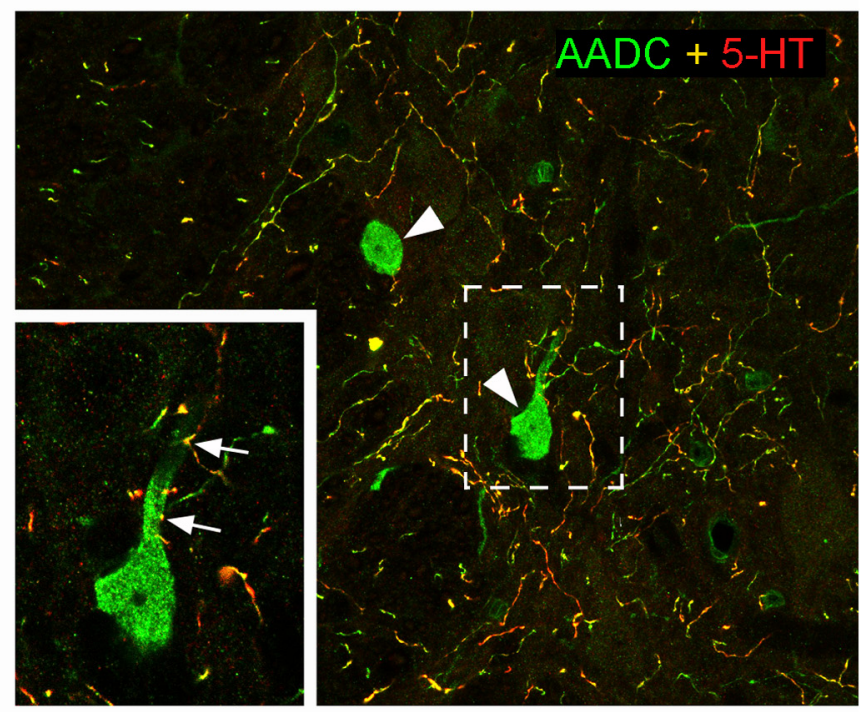

D Spinal rat - intermediate zone

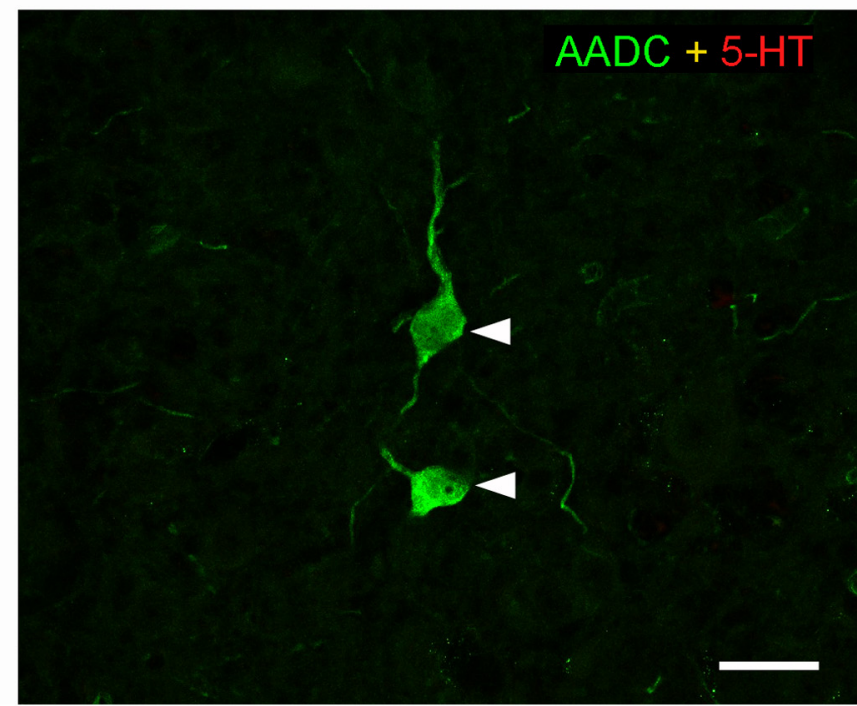

Figure 8. $A D D C$ cells in different regions of the spinal cords of normal rats receive $5-H T$ innervation from the supraspinal levels. $A-C$, Maximum $z$-projections of confocal images from normal rat spinal cords showing the relationship of the AADC cells and 5-HT fibers in the dorsal horn $(\boldsymbol{A})$, the intermediate zone $(\boldsymbol{B})$, and the region around the central canal (CC; $\boldsymbol{C}$ ). It is clear that 5-HT-immunopositive fibers (red and yellow) are distributed in different regions of the spinal cord and often in proximity to AADC cells (arrowheads). Inset in each panel is a single scan of the enlargement of the area demarcated by a broken rectangle. It can be seen that AADC cell bodies and/or their dendrites were often juxtaposed to a variable number of 5-HT fiber terminals or varicosities (arrows). $D$, In this spinal cord of a $45 \mathrm{~d}$ spinalized rat, not only are there no 5 -HT fibers from supraspinal sources in the vicinity of these AADC cells (arrows), there is also no evidence of 5-HT fibers from intraspinal sources. $\boldsymbol{A}$, From a horizontal section at Ca2. B, From a transverse section at S4. Dorsal is upward and lateral is to the left. C, From a horizontal section at S3. D, From a transverse section at $S 4$. Dorsal is upward and lateral is to the right. Scale bar, (in $\boldsymbol{D}) \boldsymbol{A}-\boldsymbol{D}, 25 \mu \mathrm{m}$.

cell expression increased by $318.0 \%$ compared with the saline control group (Fig. 9C). Thus, the percentage of AADC cells that was also 5-HT immunopositive was $10.6 \pm 5.4 \%$ in the control group and $33.7 \pm 8.2 \%$ in 5 -HT1B antagonist group. The difference between these two groups was significant ( $p<0.001$, unpaired $t$ test).

To demonstrate that 5-HT1B receptors were expressed in the AADC cells, we performed 5-HT1B immunostaining in normal and SCI rat spinal cord. First we validated the specificity of 5-HT1B antibody by adsorption experiments. The results showed that when 5-HT1B antibody was adsorbed with corresponding antigen peptide $(100 \mu \mathrm{g} / \mathrm{ml}$ antibody solution $)$ there was no or very weak 5-HT1B immunoreactivity (Fig. 10A). In normal rats, 5-HT1B immunoreactivity was widely distributed in the spinal gray matter although not all the cells were immunolabeled (Fig. 10B1,B2). The immunoreactivity was mainly located in the cytoplasm close to the cell membrane and perhaps also in the cell membrane (Fig. 10B1). The immunolabeling pattern of 5 -HT1B in the SCI rats was similar to that in the normal rats (data not shown). 5-HT1B receptors were indeed found to be expressed in the AADC cells in both the normal and spinalized rats, although not all of the AADC cells were 5-HT1B immunopositive (Fig. 10C,D).

These results indicate that $5-\mathrm{HT} 1 \mathrm{~B}$ receptor activation may inhibit the activity of AADC enzymes in their conversion of 5-HTP to 5-HT, presumably through a feedforward mechanism. However, as 5-HT1B suppressed $<30 \%$ of the 5-HT expression in the AADC cells, these results cannot exclude the possibility that other 


\section{A Spontaneous tail EMG changes in spinal rats following treatment with 5-HT1B agonist CP94253 (s.c) after 5-HTP inj (i.p)}

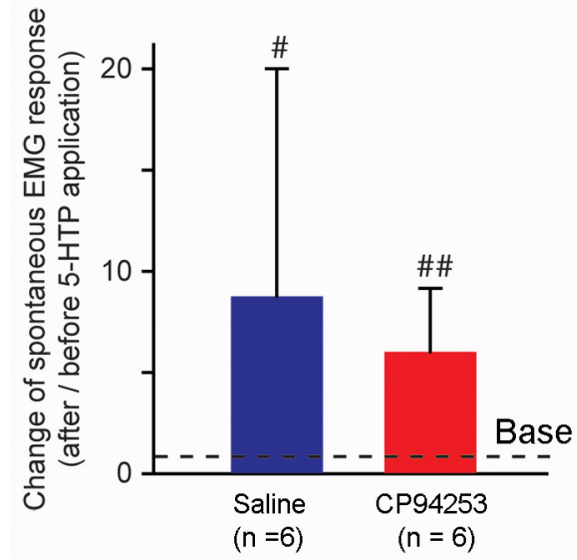

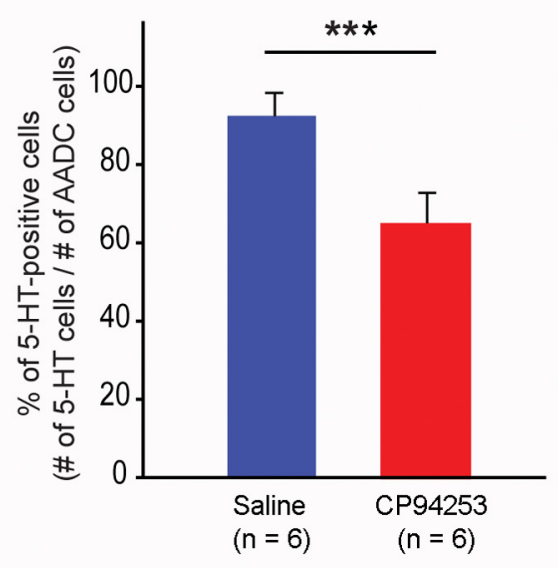

B $5-\mathrm{HT}$ expression changes in AADC cells in spinal rats following treatment with $5-\mathrm{HT} 1 \mathrm{~B}$ agonist CP94253 (s.c) after 5-HTP inj (i.p)
C 5 -HT expression changes in $A A D C$ cells in normal rats following treatment with 5-HT1B antagonist SB216641 (s.c) after 5-HTP inj (i.p)

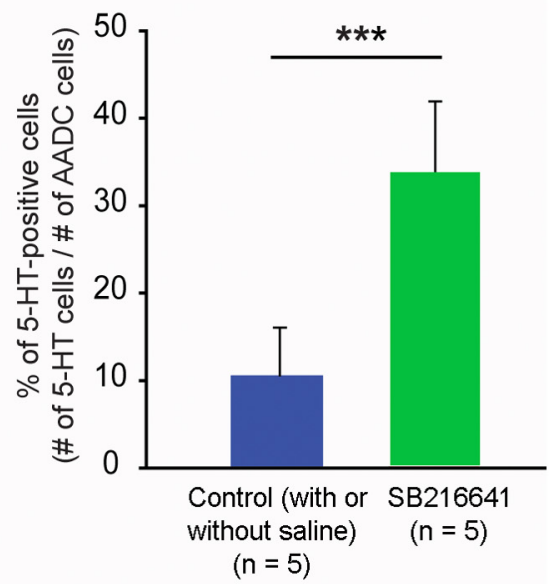

D spinal rat after CP94253 (s.c) and 5-HTP (i.p) inj E Normal rat after SB216641 (s.c) and 5-HTP (i.p) inj
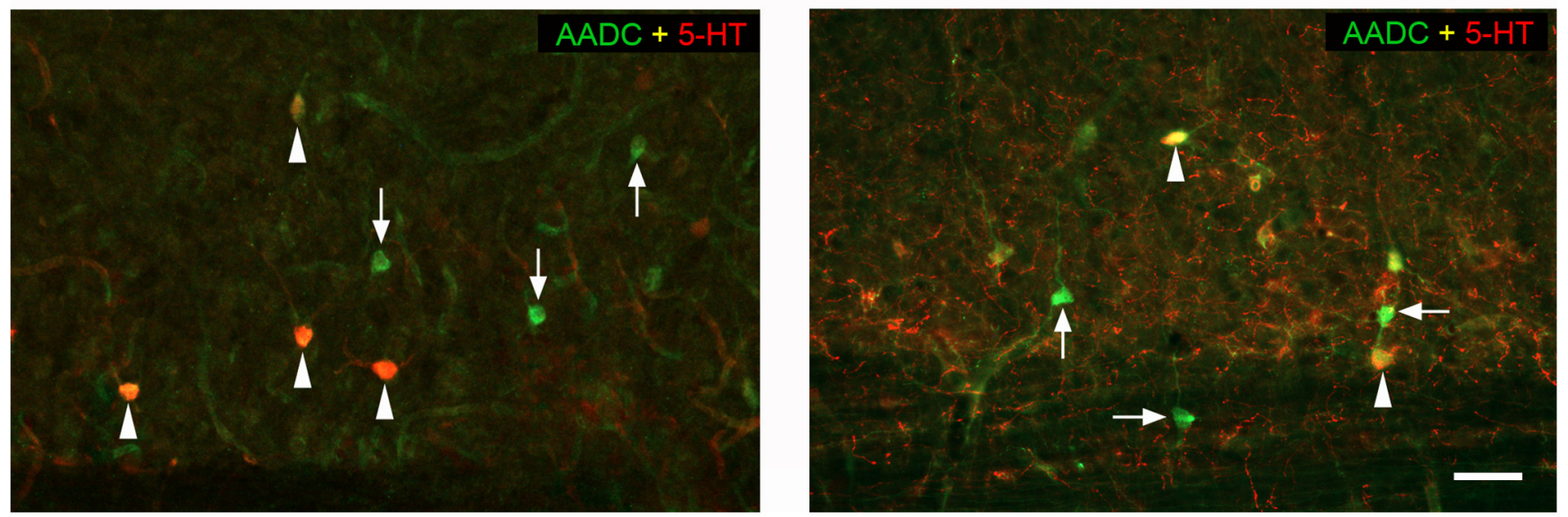

Figure 9. 5-HT1B receptors regulate the expression of 5-HT in AADC cells both in spinalized and normal rats. $A$, In spinalized rats, the increase in spontaneous tail EMG activity in response to intraperitoneal injection of 5 -HTP $(100 \mathrm{mg} / \mathrm{kg})$ was less for those pretreated with the 5 -HT1B agonist CP94253 $(0.1 \mathrm{mg} / \mathrm{kg}$, s.c.) than for saline-injected controls. Over a span of 20 min, the EMG activity in the saline control rats was $8.8 \pm 11.2$ times the baseline level (before 5 -HTP application), whereas in the (P94253-injected group, the value was $6.0 \pm 3.1$ times the baseline level, which means that CP94253 administration eliminated $\sim 36 \%$ of the EMG activity. The EMG activity in both saline control and CP94253 groups after 5 -HTP application was significantly greater than baseline $(p<0.05$ and 0.01 , respectively, in the two groups, paired $t$ test). However, due to the large variation in the saline control group, the difference between the saline control and CP94253 groups did not reach statistical significance $(p=0.70, U$ test). $\boldsymbol{B}$, Group data showing that in saline control rats $92.6 \pm 5.1 \%$ of AADC cells in the intermediate zone of the spinal cord expressed 5-HT following 5-HTP intraperitoneal injection, whereas in the (P94253-injected rats, the value was $65.7 \pm 7.5 \%$. The difference between the two groups was significant $(* * * p<0.001$, unpaired $t$ test). $C$, Following application of the 5-HT1B antagonist SB216641 (6 mg/kg, s.c.) in normal rats, the expression of 5-HT in the AADC cells was increased in response to 5-HTP intraperitoneal injection (100 $\mathrm{mg} / \mathrm{kg})$. Both with $(n=2)$ and without $(n=3$, also used in Fig. 4D) saline subcutaneous injection, $10.6 \%$ of AADC cells in the intermediate zone of the spinal cord expressed 5-HT, whereas in the SB216641-injected group, 33.7\% of AADC cells were 5-HT immunopositive. The difference between the two groups was significant ( ${ }^{* * *} p<0.001$, unpaired $t$ test). D, Microphotograph from a horizontal section through Ca1 shows the reduced incidence of 5-HT expression in the AADC cells after 5-HTP intraperitoneal injection in a $73 \mathrm{~d}$ spinalized rat that was pretreated with CP94253 (compare with Fig. 4C, which shows 5-HT immunolabeling in a chronic SCI rat without (P94253 pretreatment). $E$, Microphotograph from a horizontal section through Ca1 shows the increased incidence of 5-HT expression in the AADC cells after 5-HTP intraperitoneal injection in a normal rat that was pretreated with SB216641 (compare with Fig. 4A, which shows 5-HT labeling in a normal rat without SB216641 pretreatment). Arrowheads indicate AADC and 5-HT double-labeled cells. Arrows indicate AADC cells that do not express 5-HT. Scale bar, (in E) D, E, $50 \mu \mathrm{m}$.

5-HT1 receptors, such as 5-HT1A and 1D, may also exert an inhibitory effect.

\section{Discussion}

The present study contradicts earlier reports regarding both the distribution and function of AADC cells in the mammalian spinal cord. Our detailed anatomical study will be presented elsewhere. What is important for present purposes is that we have found both a much larger population and a wider distribution of AADC cells in the rat spinal cord than reported by others (Jaeger et al., 1983, 1984). Thus, we have found AADC cells not only in the vicinity of the central canal but also in the dorsal horn and intermediate zone of spinal cord gray matter as well as in the white matter. Moreover, we have found regional differences in the expression of selected neuronal markers by spinal cord AADC cells. For example, those around the central canal signal their immaturity by expressing NeuN weakly but doublecortin intensely, whereas those in other regions are characterized by weak expres- 


\section{A 5-HT1B antibody adsorption control}

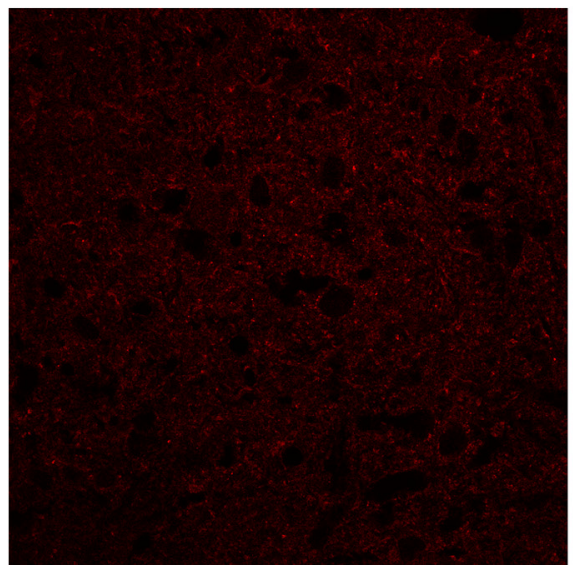

\section{B1, B2 5-HT1B expression in normal rat spinal cord} B1 5-HT1B

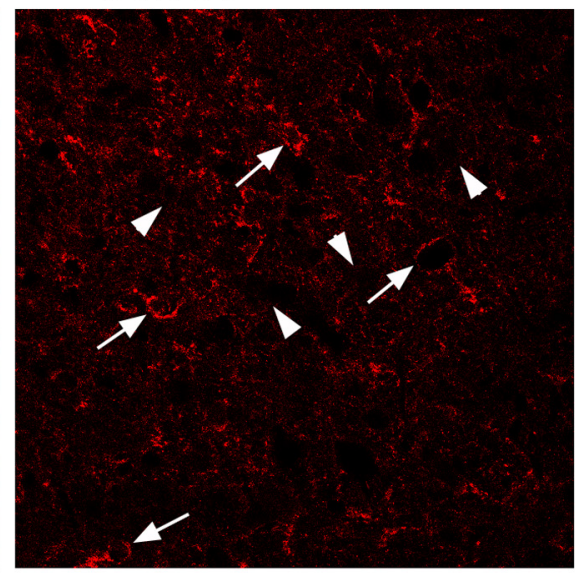

\section{Normal rat: AADC + 5- HT1B}
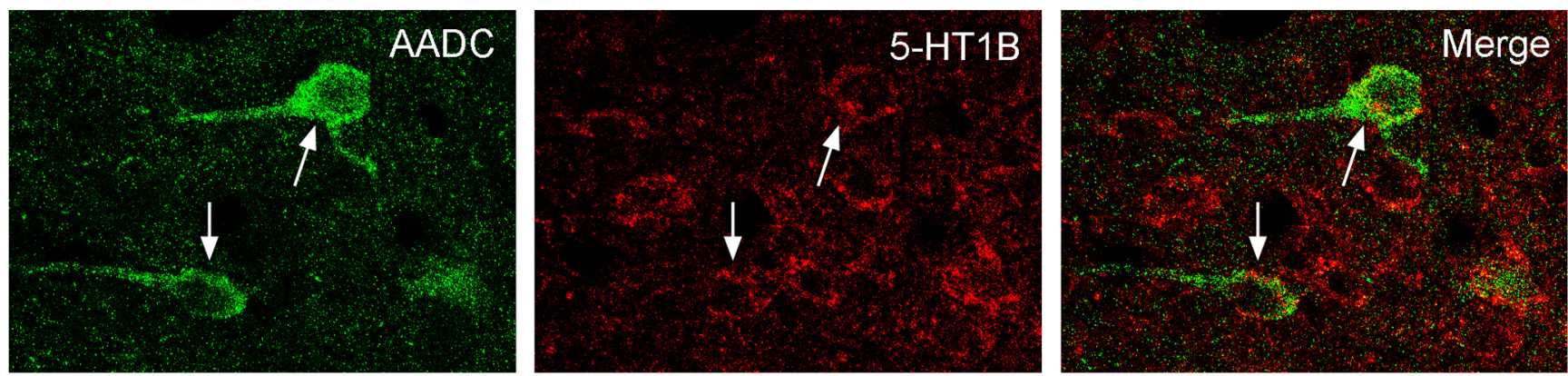

\section{Spinal rat: $A A D C+5-H T 1 B$}
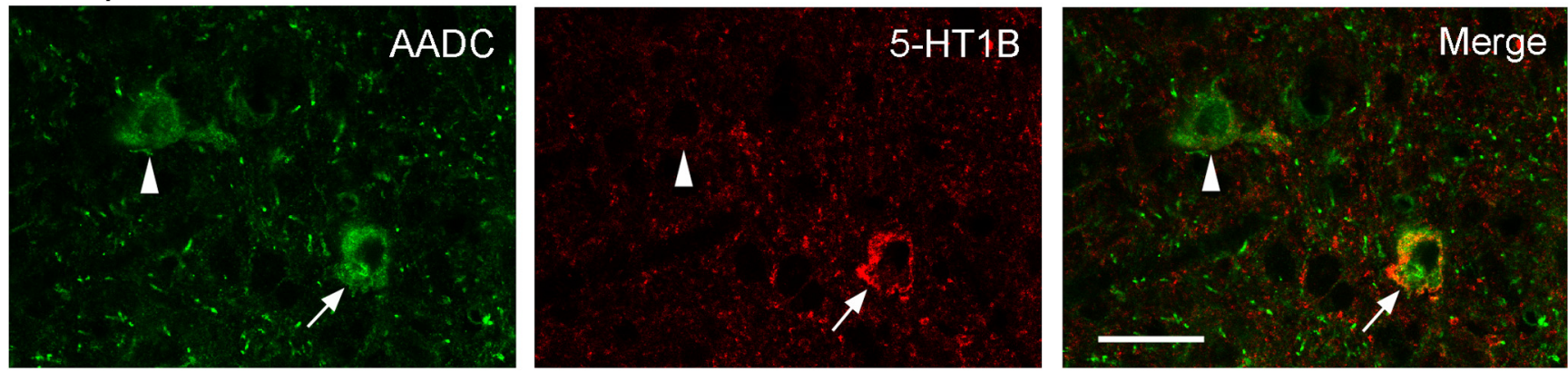

Figure 10. Confocal images showing 5-HT1B receptors were expressed in the spinal cords of both normal and spinalized rats. $A$, When 5 -HT1B antibody was adsorbed with the corresponding antigen peptide (100 $\mathrm{\mu g} / \mathrm{ml}$ antibody solution), specific immunolabeling was very weak or nonexistent. $\boldsymbol{B 1}, \mathbf{B 2}$, Images from a region in the intermediate zone of normal rat spinal cord show that 5-HT1B receptors were expressed widely in the gray matter. 5 -HT1B immunoreactivity was located in the cytoplasm and most likely also in the cell membrane (arrows). Arrowheads in $\boldsymbol{B} 1$ and $B 2$ indicate several DAPI-labeled cells that were not 5-HT1B immunopositive. $C, D$, Images showing that 5 -HT1B receptors were expressed in spinal AADC cells (arrows) in a normal (C) and a 75 day spinalized rat ( $\boldsymbol{D}$; arrows). Note that, in the spinalized rat, an AADC cell was 5-HT1B negative (arrowhead). Scale bars: (in $\boldsymbol{A 2}$ ) $\boldsymbol{A}-\boldsymbol{B 2}, 50 \mu \mathrm{m}$; (in $\boldsymbol{D}) \mathbf{C}, \boldsymbol{D}, 25 \mu \mathrm{m}$.

sion of doublecortin coupled with intense expression of NeuN, indicating that they are mature neurons. These results indicate that there might be several subpopulations of AADC cells in the spinal cord with different anatomical and functional properties.

The major physiological findings of the present study are that (1) following SCI in the rat, AADC cells caudal to the injury can produce 5-HT, provided there is a supply of 5-HTP; (2) the 5-HT produced by AADC cells following SCI is a major contributor to the hyperexcitability of motoneurons that results in muscle spasm; and (3) a mechanism underlying the increased ability of spinal cord AADC cells to produce 5-HT following SCI is their release from 5 -HT1B receptor-mediated inhibition by serotonergic innervation originating in the brainstem. These results chal- lenge two traditional notions: that 5-HT is not synthesized in the spinal cord except by the very few intraspinal 5-HT cells and that spinal AADC cells do not contain monoamines. It is likely that previous studies failed to detect the phenotypic change in AADC cells following SCI because they relied on electrophysiological methods without correlative morphological assessment. In fact, several studies from the 1970s and 1980s indicated that 5-HTP might be converted to 5-HT in spinal cord regions below a lesion (Bedard et al., 1979; Barbeau and Bédard, 1981). Bedard et al. (1979) showed that in spinalized rats systemic injection of 5-HTP, but not of 5-HT, induces motoneuron hyperexcitability and that this supersensitivity can be suppressed by the AADC inhibitor, benserazide, leading them to speculate that 5-HTP is 
decarboxylated within the CNS. A recent report from Hayashi et al. (2010) supports this concept by showing that in a contusion SCI model, 5-HTP loading, which leads to activation of all classes of 5-HT receptors, increased both weight support and hindlimb activity. Because the increased EMG response after 5-HTP application could be completely inhibited by the 5-HT2 antagonist cyproheptadine, our results indicate that, in addition to the constitutive activity of 5-HT2 receptors (Murray et al., 2010), the 5 -HT produced below the lesion may also play an important role in enhancing motoneuron excitability by acting on the upregulated 5-HT2 receptors. Our previous and present studies indicate that this effect could be exerted not only via receptors on interneurons but also via direct interactions between fibers from AADC cells, which are 5-HT positive after 5-HTP application (Fig. 5) and ventral horn motoneurons, which exhibit intense expression of 5-HT2 receptors (Kong et al., 2010, 2011; Ren et al., 2013).

Our results also indicate that the plastic properties of some neurons in the spinal cord include the ability to become alternative sources of innervation normally supplied by supraspinal sources. Of course, the plasticity of the 5-HT system does not stand alone. Indeed, plastic changes following SCI include the upregulation or downregulation of many different transmitter receptors (Giroux et al., 1999; Harvey et al., 2006; Kong et al., 2010, 2011; Murray et al., 2010; Ren et al., 2013) and ion transporters (Boulenguez et al., 2010) as well as the formation of new intraspinal circuits (Krenz and Weaver, 1998; Bareyre et al., 2004). Interneurons constitute the largest population of neurons in the spinal cord, and the locations of AADC cells in the spinal cord suggest that they are part of the interneuron pool. The plastic changes of interneurons after SCI are important for the recovery of motor function. For example, after complete spinal transection adult rats can experience some recovery of gait after a few weeks (Ribotta et al., 2000; Orsal et al., 2002; Rossignol et al., 2011). Early in development, some interneurons express a phenotype characteristic of 5-HT neurons in the brain but later lose this phenotype. For example, Branchereau et al. (2002) showed that in organotypic cultures of embryonic mouse (E14.5-E18.5) many 5-HT neurons were present throughout the spinal cord when it was cultured in isolation, but could not be detected in cultures that included medulla oblongata. It remains to be learned whether the suppressed 5-HT cells in such cultures represent the spinal AADC cells of adult animals, which can recover the capacity to produce 5-HT after SCI. In any event, it seems certain that the spinal cord contains a distributed reservoir of "interneurons-in-waiting" and that, following SCI, their potential is unmasked and they assume functions normally exerted by supraspinal 5-HT sources.

One of the aims of the present study was to investigate the mechanism by which SCI enhances AADC activity. We speculate that, in normal animals, AADC activity is inhibited by $5-\mathrm{HT}$ innervation from the brainstem by a feedforward mechanism that involves activation of 5-HT receptors in AADC cells. In the brain, 5-HT1B, as well as 5-HT1A and 5-HT1D, has been identified as an autoreceptor with the ability to reduce 5-HT released from brainstem raphe nuclei (Davidson and Stamford, 1995; Hopwood and Stamford, 2001) and several other brain regions (Hervás and Artigas, 1998; Knobelman et al., 2001; de Groote et al., 2002). In the spinal cord 5-HT1B receptors seem to be more important than 5-HT1A receptors in regulating the release of 5-HT from 5-HT fiber terminals (Monroe and Smith, 1985; Brown et al., 1988; Murphy and Zemlan, 1988). The results from our 5-HT1B agonist and antagonist experiments demonstrate that $5-\mathrm{HT} 1 \mathrm{~B}$ receptors are able to regulate the ability of AADC cells to synthesize 5-HT after SCI. However, these results do not exclude a critical role of 5-HT1A in its inhibitory effect on AADC cells in an intact spinal cord because 5-HT1B could only partly control the ability of the spinal AADC cells to synthesize 5-HT from 5-HTP (Fig. 9). This assumption receives support from a study by Branchereau et al. (2002), who showed that when a 5-HT1A antagonist is added to the culture medium, spinal cord cocultured with brainstem will express the 5-HT phenotype. As noted above, it is not known whether these 5-HT-positive cells are equivalent to AADC cells in the adult spinal cord, but their expression of 5-HT makes it plausible that they contain the enzyme AADC.

An unsolved issue in this study is the intraspinal origin of 5 -HTP below the transection. One possible source might be CSF, although the amount it can supply is very low $(\sim 0.012 \mu \mathrm{M}$ in rats on average; Le Quan-Bui et al., 1982). What is certain is that, even without external 5-HTP application, 5-HT can be synthesized in the spinal cord below the transection. For instance, following application of the MAOI pargyline without 5-HTP, 5-HT content in the spinal cord below the transection is increased 8.5 -fold (Hadjiconstantinou et al., 1984). The results from our in vitro experiments demonstrate that benserazide alone can reduce the duration and amplitude of LLRs (Fig. 7D1), suggesting that AADC cells might be constantly active in the production of small amounts of monoamine transmitters. Although we have unpublished data showing that if only an MAOI is given, no 5-HTimmunopositive AADC cells are to be found, this is probably because current immunohistochemical methods are not sufficiently sensitive to detect the extremely small amounts of 5-HT that may be present in these cells.

In summary, our results demonstrate that an unexpected plasticity can occur for the spinal neurons in response to SCI, which may lead to pathophysiological dysfunction such as spasms and hyperreflexia of the tail. However, balancing this downside, it is well documented that at the lumbar level, the presence of 5-HT (or activation of certain types of 5-HT receptors) is of fundamental importance for the recovery of physiological functions, e.g., locomotion, after SCI (Orsal et al., 2002; Schmidt and Jordan, 2000; Antri et al., 2005). It should be emphasized that the results emerging from the present model system may have substantial relevance for the L-dopa-induced dyskinesia observed in advanced cases of Parkinson's disease (Cenci, 2007; Nahimi et al., 2012) because AADC-only cells in the brain could use L-dopa to produce dopamine (Karasawa et al., 1994; Ugrumov, 2009).

\section{References}

Anelli R, Sanelli L, Bennett DJ, Heckman CJ (2007) Expression of L-type calcium channel alpha(1)-1.2 and alpha(1)-1.3 subunits on rat sacral motoneurons following chronic spinal cord injury. Neuroscience 145:751763. CrossRef Medline

Antri M, Barthe JY, Mouffle C, Orsal D (2005) Long-lasting recovery of locomotor function in chronic spinal rat following chronic combined pharmacological stimulation of serotonergic receptors with 8-OHDPAT and quipazine. Neurosci Lett 384:162-167. CrossRef Medline

Barbeau H, Bédard P (1981) Denervation supersensitivity to 5-hydroxytryptophan in rats following spinal transection and 5,7-dihydroxytryptamine injection. Neuropharmacology 20:611-616. CrossRef Medline

Bareyre FM, Kerschensteiner M, Raineteau O, Mettenleiter TC, Weinmann O, Schwab ME (2004) The injured spinal cord spontaneously forms a new intraspinal circuit in adult rats. Nat Neurosci 7:269-277. CrossRef Medline

Bedard P, Barbeau H, Barbeau G, Filion M (1979) Progressive increase of motor activity induced by 5-HTP in the rat below a complete section of the spinal cord. Brain Res 169:393-397. CrossRef Medline 
Bennett DJ, Gorassini M, Fouad K, Sanelli L, Han Y, Cheng J (1999) Spasticity in rats with sacral spinal cord injury. J Neurotrauma 16:69-84. CrossRef Medline

Bennett DJ, Sanelli L, Cooke CL, Harvey PJ, Gorassini MA (2004) Spastic long-lasting reflexes in the awake rat after sacral spinal cord injury. J Neurophysiol 91:2247-2258. CrossRef Medline

Boulenguez P, Liabeuf S, Bos R, Bras H, Jean-Xavier C, Brocard C, Stil A, Darbon P, Cattaert D, Delpire E, Marsala M, Vinay L (2010) Downregulation of the potassium-chloride cotransporter KCC2 contributes to spasticity after spinal cord injury. Nat Med 16:302-307. CrossRef Medline

Branchereau P, Chapron J, Meyrand P (2002) Descending 5-hydroxytryptamine raphe inputs repress the expression of serotonergic neurons and slow the maturation of inhibitory systems in mouse embryonic spinal cord. J Neurosci 22: 2598-2606. Medline

Brown L, Amedro J, Williams G, Smith D (1988) A pharmacological analysis of the rat spinal cord serotonin (5-HT) autoreceptor. Eur J Pharmacol 145:163-171. CrossRef Medline

Cenci MA (2007) Dopamine dysregulation of movement control in L-DOPA-induced dyskinesia. Trends Neurosci 30:236-243. CrossRef Medline

Christenson JG, Dairman W, Udenfriend S (1972) On the identity of DOPA decarboxylase and 5-hydroxytryptophan decarboxylase (immunological titrationaromatic L-amino acid decarboxylase-serotonin-dopamine-norepinephrine). Proc Natl Acad Sci U S A 69:343-347. CrossRef Medline

Clineschmidt BV, Pierce JE, Lovenberg W (1971) Tryptophan hydroxylase and serotonin in spinal cord and brain stem before and after chronic transection. J Neurochem 18:1593-1596. CrossRef Medline

Davidson C, Stamford JA (1995) Evidence that 5-hydroxytryptamine release in rat dorsal raphé nucleus is controlled by 5-HT1A, 5-HT1B and 5-HT1D autoreceptors. Br J Pharmacol 114:1107-1109. CrossRef Medline

de Groote L, Olivier B, Westenberg HG (2002) Extracellular serotonin in the prefrontal cortex is limited through terminal 5-HT(1B) autoreceptors: a microdialysis study in knockout mice. Psychopharmacology 162:419424. CrossRef Medline

Eaton MJ, Gudehithlu KP, Quach T, Silvia CP, Hadjiconstantinou M, Neff NH (1993) Distribution of aromatic L-amino acid decarboxylase mRNA in mouse brain by in situ hybridization histology. J Comp Neurol 337:640-654. CrossRef Medline

Giroux N, Rossignol S, Reader TA (1999) Autoradiographic study of alpha1- and alpha2-noradrenergic and serotonin $1 \mathrm{~A}$ receptors in the spinal cord of normal and chronically transected cats. J Comp Neurol 406: 402-414. CrossRef Medline

Hadjiconstantinou M, Panula P, Lackovic Z, Neff NH (1984) Spinal cord serotonin: a biochemical and immunohistochemical study following transection. Brain Res 322:245-254. CrossRef Medline

Harvey PJ, Li X, Li Y, Bennett DJ (2006) Endogenous monoamine receptor activation is essential for enabling persistent sodium currents and repetitive firing in rat spinal motoneurons. J Neurophysiol 96:1171-1186. CrossRef Medline

Hayashi Y, Jacob-Vadakot S, Dugan EA, McBride S, Olexa R, Simansky K, Murray M, Shumsky JS (2010) 5-HT precursor loading, but not 5-HT receptor agonists, increases motor function after spinal cord contusion in adult rats. Exp Neurol 221:68-78. CrossRef Medline

Hervás I, Artigas F (1998) Effect of fluoxetine on extracellular 5-hydroxytryptamine in rat brain. Role of 5-HT autoreceptors. Eur J Pharmacol 358:9-18. CrossRef Medline

Hökfelt T, Fuxe K, Goldstein M (1973) Immunohistochemical localization of aromatic L-amino acid decarboxylase (DOPA decarboxylase) in central dopamine and 5-hydroxytryptamine nerve cell bodies of the rat. Brain Res 53:175-180. CrossRef Medline

Hopwood SE, Stamford JA (2001) Multiple 5-HT(1) autoreceptor subtypes govern serotonin release in dorsal and median raphé nuclei. Neuropharmacology 40:508-519. CrossRef Medline

Jaeger CB, Teitelman G, Joh TH, Albert VR, Park DH, Reis DJ (1983) Some neurons of the rat central nervous system contain aromatic-L-amino-acid decarboxylase but not monoamines. Science 219:1233-1235. CrossRef Medline

Jaeger CB, Ruggiero DA, Albert VR, Joh TH, Reis DJ (1984) Immunocytochemical localization of aromatic-l-aminoacid decarboxylase. In: Handbook of chemical neuroanatomy. Classical transmitters in the CNS, Part I, Vol. 2 (Björklund A, Hökfelt T, eds), pp 387-408. Amsterdam: Elsevier.

Karasawa N, Arai R, Isomura G, Yamada K, Sakai K, Sakai M, Nagatsu T,
Nagatsu I (1994) Phenotypic changes of AADC-only immunopositive premammillary neurons in the brain of laboratory shrew Suncus murinus by systemic administration of monoamine precursors. Neurosci Lett 179: 65-70. CrossRef Medline

Kitahama K, Ikemoto K, Jouvet A, Araneda S, Nagatsu I, Raynaud B, Nishimura A, Nishi K, Niwa S (2009) Aromatic L-amino acid decarboxylase-immunoreactive structures in human midbrain, pons, and medulla. J Chem Neuroanat 38:130-140. CrossRef Medline

Knobelman DA, Hen R, Lucki I (2001) Genetic regulation of extracellular serotonin by 5 -hydroxytryptamine(1A) and 5 -hydroxytryptamine(1B) autoreceptors in different brain regions of the mouse. J Pharmacol Exp Ther 298:1083-1091. Medline

Kong XY, Wienecke J, Hultborn H, Zhang M (2010) Robust upregulation of serotonin $2 \mathrm{~A}$ receptors after chronic spinal transection of rats: an immunohistochemical study. Brain Res 1320:60-68. CrossRef Medline

Kong XY, Wienecke J, Chen M, Hultborn H, Zhang M (2011) The time course of serotonin $2 \mathrm{~A}$ receptor expression after spinal transection of rats: an immunohistochemical study. Neuroscience 177:114-126. CrossRef Medline

Krenz NR, Weaver LC (1998) Sprouting of primary afferent fibers after spinal cord transection in the rat. Neuroscience 85:443-458. CrossRef Medline

Le Quan-Bui KH, Elghozi JL, Devynck MA, Meyer P (1982) Rapid liquid chromatographic determination of 5-hydroxyindoles and dihydroxyphenylacetic acid in cerebrospinal fluid of the rat. Eur J Pharmacol 81:315320. CrossRef Medline

Li X, Murray K, Harvey PJ, Ballou EW, Bennett DJ (2007) Serotonin facilitates a persistent calcium current in motoneurons of rats with and without chronic spinal cord injury. J Neurophysiol 97:1236-1246. Medline

Li Y, Harvey PJ, Li X, Bennett DJ (2004) Spastic long-lasting reflexes of the chronic spinal rat studied in vitro. J Neurophysiol 91:2236-2246. CrossRef Medline

Lovenberg W, Weissbach H, Udenfriend S (1962) Aromatic L-amino acid decarboxylase. J Biol Chem 237:89-93. Medline

Magnusson T (1973) Effect of chronic transection on dopamine, noradrenaline and 5-hydroxytryptamine in the rat spinal cord. Naunyn Schmiedebergs Arch Pharmacol 278:13-22. CrossRef Medline

Monroe PJ, Smith DJ (1985) Demonstration of an autoreceptor modulating the release of [3H]5-hydroxytryptamine from a synaptosomal-rich spinal cord tissue preparation. J Neurochem 45:1886-1894. CrossRef Medline

Murphy RM, Zemlan FP (1988) Selective 5-HT1B agonists identify the 5 -HT autoreceptor in lumbar spinal cord of rat. Neuropharmacology 27:37-42. CrossRef Medline

Murray KC, Nakae A, Stephens MJ, Rank M, D’Amico J, Harvey PJ, Li X, Harris RL, Ballou EW, Anelli R, Heckman CJ, Mashimo T, Vavrek R, Sanelli L, Gorassini MA, Bennett DJ, Fouad K (2010) Recovery of motoneuron and locomotor function after spinal cord injury depends on constitutive activity in 5-HT2C receptors. Nat Med 16:694-700. CrossRef Medline

Nagatsu I, Sakai M, Yoshida M, Nagatsu T (1988) Aromatic L-amino acid decarboxylase-immunoreactive neurons in and around the cerebrospinal fluid-contacting neurons of the central canal do not contain dopamine or serotonin in the mouse and rat spinal cord. Brain Res 475:91-102. CrossRef Medline

Nahimi A, Høltzermann M, Landau AM, Simonsen M, Jakobsen S, Alstrup AK, Vang K, Møller A, Wegener G, Gjedde A, Doudet DJ (2012) Serotonergic modulation of receptor occupancy in rats treated with L-DOPA after unilateral 6-OHDA lesioning. J Neurochem 120:806-817. CrossRef Medline

Newton BW, Hamill RW (1988) The morphology and distribution of rat serotoninergic intraspinal neurons: an immunohistochemical study. Brain Res Bull 20:349-360. CrossRef Medline

Newton BW, Maley BE, Hamill RW (1986) Immunohistochemical demonstration of serotonin neurons in autonomic regions of the rat spinal cord. Brain Res 376:155-163. CrossRef Medline

Nielsen JB, Crone C, Hultborn H (2007) The spinal pathophysiology of spasticity-from a basic science point of view. Acta Physiol 189:171-180. CrossRef Medline

Orsal D, Barthe JY, Antri M, Feraboli-Lohnherr D, Yakovleff A, Giménez y Ribotta M, Privat A, Provencher J, Rossignol S (2002) Locomotor recovery in chronic spinal rat: long-term pharmacological treatment or trans- 
plantation of embryonic neurons? Prog Brain Res 137:213-230. CrossRef Medline

Ren LQ, Wienecke J, Chen M, Guo S, Ma Q, Zheng XY, Li HY, Kong XY, Zhao SM, Hultborn H, Zhang M (2012) Aromatic L-amino acid decarboxylase cells in spinal cord could potentially provide serotonin but not dopamine after complete spinal cord transection. Soc Neurosci Abstr 38:182.10.

Ren LQ, Wienecke J, Chen M, Møller M, Hultborn H, Zhang M (2013) The time course of serotonin $2 \mathrm{C}$ receptor expression after spinal transection of rats: an immunohistochemical study. Neuroscience 236:31-46. CrossRef Medline

Ribotta MG, Provencher J, Feraboli-Lohnherr D, Rossignol S, Privat A, Orsal D (2000) Activation of locomotion in adult chronic spinal rats is achieved by transplantation of embryonic raphe cells reinnervating a precise lumbar level. J Neurosci 20:5144-5152. Medline

Rossignol S, Frigon A, Barrière G, Martinez M, Barthélemy D, Bouyer L, Bélanger M, Provencher J, Chau C, Brustein E, Barbeau H, Giroux N, Marcoux J, Langlet C, Alluin O (2011) Chapter 16-spinal plasticity in the recovery of locomotion. Prog Brain Res 188:229-241. CrossRef Medline
Roy RR, Edgerton VR (2012) Neurobiological perspective of spasticity as occurs after a spinal cord injury. Exp Neurol 235:116-122. CrossRef Medline

Schmidt BJ, Jordan LM (2000) The role of serotonin in reflex modulation and locomotor rhythm production in the mammalian spinal cord. Brain Res Bull 53:689-710. CrossRef Medline

Ugrumov MV (2009) Non-dopaminergic neurons partly expressing dopaminergic phenotype: distribution in the brain, development and functional significance. J Chem Neuroanat 38:241-256. CrossRef Medline

Wienecke J, Westerdahl AC, Hultborn H, Kiehn O, Ryge J (2010) Global gene expression analysis of rodent motoneurons following spinal cord injury associates molecular mechanisms with development of postinjury spasticity. J Neurophysiol 103:761-778. CrossRef Medline

Wienecke J, Ren L, Hultborn H, Zhang M (2012) Motoneuronal hyperexcitability is caused by aromatic L-amino acid decarboxylase production of serotonin. Soc Neurosci Abstr 38:182.9.

Zhang M, Chen M, Ren L, Wienecke J (2012) Aromatic L-amino acid decarboxylase cells are widely distributed in the rat spinal cord. Soc Neurosci Abstr 38:182.11. 